\title{
DESIGN OF DUPLEX LOH-CARBON STEELS \\ WITH CARBIDE FORMING ELEMENTS
}

\author{
Peter X. Cositello
}

(M.S. Thesis)

December 1978

\section{Prepared for the U.S. Department of Energy under contract $W-7405-E N G-48$}

\footnotetext{
This Notice

report was prepaied an account of work woncred by the Uniled States Government. Neither the Eniled States not the United Stales Desayimenl of Enerzy, hat any of theis employees, nor any of their

contisctors, subronumactors, or their employees, makes

any warmanty. expreus or tmplied, or assumes any legal

tisbility or retponsibility fint the aceuracy, completentess

or uxfulnes of any information, apparalus, product of

proces dixtlosed, or teprisents that its tse would nat

Infringe privately owned rights.
} 
DESIGN OF DUPLEX LOW-CARBON STEELS NITH

CARBIDE FORMING ELEMENTS

Peter X. Costello

Materials and Molecular Research Division, Lawrence Berkeley Laboratory and Department of Materials Science and Mineral Engineering University of California, Berkeley, California 94720

\section{ABSTRACT}

This is an investigation concerns the design of duplex ferritemartensite (DFM) steels with carbide forming elements. The quaternary alloys $\mathrm{Fe} / 0.14 \mathrm{C} / 1.45 \mathrm{Si} / \mathrm{X}$ (X being the stbstitutional alloying element of Mo or $\mathrm{Nb}$ ) have been selected from first principles. The DFM micrastructures are controlled by the type of alloy element $\mathrm{X}$ and the subsequent thermal treatment: The tensile properties of specimens subjected to either the intermediate quench (IQ) or the intermediate air cool (IAC) heat treatments have been cortelated with their ressective microstructures.

Dispersion hardening as a secondary strengthening mechanism is found to limit the ductility whilst increasing the strength due to carbide precipitation in the ferrite. As a result, unusual behavior in the strength-law of mixtures relationship is observed.

The differences in properties displayed by the alloys between the IQ and IAC thermal treatments are primarily attributed to the connectivity of the martensite particles. The IQ treatment provided strength and elongation ductility (i.e., total or uniform elongation to deformation) combinations which are superior to those of the IAC process. Specifically, the niobium steel displayed the best mechanical properties. 
The limited investigation of the alloys subjected to a continuo:s air cooling (from austenite region) neat treatmenc provided specimens with supericr elongation ductility a compared to some of the coumercially available HSLA sreels. These microstructures contsin proeutectoid ferrite plus other isothermal products. This process appears to be an attractive one for potential technical applications. 
I. Introduction. . . . . . . . . . . . . . . . . . 1

II. Experimental Procedure. . . . . . . . . . . . . . . 4

A. Material Selection. . . . . . . . . . . . . 4

B. Materials Preparation . . . . . . . . . . . . 7

c, Heat Treating . . . . . . . . . . . . . . . 7

1. Intermediate Quench Treatment . . . . . . . 8

2. Intermediate Air Cool Treatment . . . . . . . 9

3. Continuous Air Cooling from Austenite Region. . . 9

D. Mechanical Testing. . . . . . . . . . . . . 10

E. Metallography .................... . 11

1. Optical Metallography .............. 11

2. Transmission Electron Microscopy. . . . . . . . 11

III. Resuits and Discussion. . . . . . . . . . . . . 13

A. Microstructures . . . . . . . . . . . . 13

1. Intermediate Quench vs. Intermediate Air Cool . . 13

2. Continuous Air Cooling from Austenite Region. . . 17

3. Microstructural Comparison of $\mathrm{Fe} / 0.15 \mathrm{c} / 1.45 \mathrm{Si} /$

$0.38 \mathrm{Mo}$ vs. Fe/0.14 C/1.45 Si/0.034 $\mathrm{Nb} . . . .17$

a. Intermediate Quench Treatment . . . . . . 17

b. Intermediate Air Cool Treatment . . . . . . 19

c. Continuous Air Cooling from Austenite Region. - 19

B. Mechanical Properties. . . . . . . . . . . 20

1. Overall Comparison of the Various Heat Treatments 20 
2. Mechanical Property Comparison of $\mathrm{Fe} / 0.15 \mathrm{c} / 1.45 \mathrm{si} / 0.38 \mathrm{wo}$ vs. Fe/0.14 C/1.45 Si/0.034 Nb. ........... 21

a. Intermediate Quench Treatment . . . . . . . 22

b. Intermediate Air Cool Treatment . . . . . . 22

c. Continuous Air Cooling from Austenite Region. - 22

C. Mechanical Property/Microstructure Correlations . . . . 22

1. Strengthening Mechanisms. . . . . . . . . . . 22

2. Qualitative Relationship.......... . 24

D. Comparison to Some Commercially Available

HSLA and Other DFM Steels............. . 27

IV. Conclusion. . . . . . . . . . . . . . . . . . 28

Acknowledgements. . . . . . . . . . . . . . . . . . 30

References. . . . . . . . . . . . . . . . . . . 31

Tables. . . . . . . . . . . . . . . . . . . 33

Figure Captions. . . . . . . . . . . . . . . . . 36

Figures . . . • . . . . . . . . . . . . . . . . . 39 


\section{INTRODUCTION}

The need for higher strength steels with good formability for energy and resource conservation requirements, has triggered intensive development programs in the area of low-carbon, low-alloy steels. It has already been realized in conventional high strength, low-ailoy (HSLA) steels, that the overall mechanical properties along with the alloying and processing economics are not always satisfactory for many applications. Emphasis on alternatives has spurred the recent development of duplex ferrite-martensite (DFH) steels. ${ }^{1-6}$ These "neometalloids" are a new breed of HSLA steels displaying improved formability with superior strength and are formed by a simpler (more economical) processing technique.

The processing of steels to produce a microduplex structure of martensite in a ferrite matrix, is not an entirely new conceft as pointed out by Koo. ${ }^{5}$ Cairns and Charies ${ }^{7}$ considered DFM structures as possible materials of technological interest by instituting a program aimed at developing laminates and composites through combinations of mechanical work and thermal treatments. Although they were successful in producing controlled microstructures of elongated regions of martensite in a ferrile matrix, only limited success was achieved with commercial steels. Grange ${ }^{3}$ approached the concept of DFM aggregates chrough thermo-mechanical tratments. Fibrous mixtures of martensite and ferrice were actiluved by utilizing the phase transformation cccurring in the wo-phase, ferrite plus austenite $(\alpha+\gamma)$ region of the Fe-C agstem. However, the processing technique is complex and only limited success in improving mechanical properties 
was achieved. As a consequence of these studies, Koo ${ }^{3,5}$, Koo and Thomas 1,2 and Young ${ }^{4}$ have modified the processing techniques of Grange to employ solely a mpl thermal treatment incorporating two-phase annealing with selected comercial and experimental low-carbon steels. The improved elongation ductility and superior strength have been overwhelmingly demonstrated.

The advantages of duplex microstructures have been established in several alloy systems as documented by Koo and Thomas ${ }^{5}$ in the previou $y$ noted literature. Applications to low-carbon, low-alloy steels are especially interesting for several reasons: (1) the capability of optimizing the ever conflicting property requirements of strength and ductility, contingent upon a favorable choice of alloy composition and processing; ${ }^{2,9}$ (2) simple alloy compositional requirements; (3) the required composite microstructures can be produced by a simple heat treatment alone; (4) a wide range of attractive strength and ductility combinations are possible.

The earlier work on DFM aggregates have been primarily concerned with the influence of the volume fraction or strength of the second phase (i.e., martensite) on the mechanical properties. Although this observation is important, a complete fundamental understanding of the microstructure-mechanical property relationships is incomplete. Furtherwore, an understanding of the efiect of alloy carbides in the ferrite matrix on the mechanical behavior of the DFM aggregate is lacking.

This investigation is designed to consider alloy carbide precipitation in the ferrite matrix as a secondary strengthening mechanism. 
The conceptual implications are that a desired atrength level 0 may be achieved by a lower volume fraction of martensite ( $V_{m}=1-v_{f}$ ), since the strength is empirically given by $\sigma=\sigma_{f}(1-V m)+\sigma_{m b m}$, where $\sigma_{f}$ and $\sigma m$ are the strengths of ferrite and martensite, respectively. 1,2 The consequent higher volume fraction $v_{f}$ of ferrite could provide improved ductility. Whether or not the elongation ductility and the tensile/yizld strength ratio is to be penalized, due to an alloy carbideriddled ferrite matrix, is also to be evaluated. Thus the objectives of this thesis research are:

(1) to establish the influence of the alloy carbides on the tensile properties of the DFM aggregate.

(2) to investigate a variety of simple heat creatments and the resulting mechanical properties.

(3) to characterize the microstructures of the duplex steels in terms of size, shape and distribution of the load carrying constituent (i.e., martensite phase).

(4) to characterize the substructure of the DFM aggregate in regards to the presence of retained austenite, alloy carbide precipitation, dislocations and subgrains, martensite substructure. 


\section{EXPERIMENTAL PROCEDURE}

\section{A. Material Selection}

The low-carbon, low-alloy ateels selected for this study are the quarternary alloys of the type Fe/0.15 $\mathrm{C} / 1.45 \mathrm{si} / \mathrm{X}$. The substitutional alloying element $X$ has been chosen to be molybdenum or niobium. The ternary Fe/C/Si alloy has been selected as the base material. This alloy, displaying outstanding mechanical properties, has been extensively characterized. 5 The following is the basis for the selection of each alloying element from first principlea.

Silicon (1.45 wt. pct.)

(1) Silicon, in amounts around 2 wt. pct., promotes a fine fibrous distribution of martensite in a continuous ferrite matrix. 5 Load transfer is most efficient when particies are present in the form of fibers rather than spheres. This is primarily because the transfer of load occurs by shear action along the particle matrix interfaces. 10 Hence for a givan $\mathrm{Vm}$ and the same number of particles, more interfacial area is available in the case of a fibrous morphology. Since silicon promotes a continuous ferrite matrix, the connectivity of the martensite particles can be avoided throughout the aggregate. This may prevent continuous crack propagation in the early stages of plastic deformation and allows the ferrite to contribute its full ductility to the system. 
(2) Silicon inhibits the formation of coarse carbides (i.e., $\mathrm{Fe}_{3} \mathrm{C}$ ) due to isothermal decompositior of austenite during the final quench. Improving the hardenability is important since the DFM alloys are designed to be low in carbon. These carbides, if any, will be located near the ferrite/ martensite interface. This is undesirable because the presence of $\mathrm{Fe}_{3} \mathrm{C}$ particles may cause local stress concentrations promoting the formation of cracks within these carbides leading to the ultimate failure of the system when subjected to an external load. 11 The amount of silicon has been reduced in these steels since the other alloys are expected to compensate for hardenability.

(3) Silicon increases the slope of the $A_{3}$ line in the $(\alpha+y)$ range when added to the Fe-C system as shown in Fig. 3 . This facilitates practical control of the strong phase (i.e., Vm).

(4) Silicon provides effective solid solution strengthening in the ferrite.

Carbon ( 0.14 wt. pct.)

(1) Martensite is a diffusionless transformation product sf carbon enriched austenite. In other words, the carbon content in the martensite is determined by that of the austenite. It is desirable to maintain a carbon level of about 0.3 wt. pct. in the austenite, resulting in a dis located martensite. Higher carbon contents can drastically deteriorate the toughness of martensite. 12 
In order to produce a $0.3 \mathrm{wt}$. pet. carbon content of the alloy should be less than 0.1 wt. pet. This can be seen in Fig. 3 by drawing tie line in the lower portion of the $(\alpha+\gamma)$ region. The actual carbon contents of the alloys melted for thig investigation are slightly higher than was specified.

(2) Low cost and availability.

Molybdenum $(0.38$ wt. pct.)

(1) Molybdenum is a strong carbide forming element ${ }^{13}$ (i.e., $\left.\mathrm{Mo}_{2} \mathrm{C}\right)$. After annealing in the lower portion of che $(\alpha+\gamma)$ region the ferrite will be carbon supersaturated. This carbon content in the ferrite is about 100-200 times greater than normal at room temperature. Hence, 0.38 wt. pet. molybdenum has been added to tie up this excess carbon in the ferrite in the form of alloy carbides.

(2) Molybdenum improves grain boundary properties.

(3) Molybdenum increases the hardenability of the system. Practically, this is desired in order to process larger gauge sections by avoiding undesirable transformation products.

(4) It provides moderate solid solution strengthening. 13

(5) Molybdenum increases the slope of the $A_{3}$ line in the $(\alpha+\gamma)$ region. 
Niobium (0.034 wt. pct.)

(1) Niobium is a strong carbide forming element ${ }^{13}$ (NbC). The reason for the amount of niobium added to the $\mathrm{Fe} / \mathrm{C} / \mathrm{Si} / \mathrm{X}$ alloy is analogous to that for molybdenum.

(2) Niobium increases the hardensbility of the system.

(3) It incrases the slope of the $A_{3}$ line.

(4) It provides for prior austenite grain size refinement.

\section{B. Materials Preparation}

The materials uged in this investigation were melted under an argon atmosphere and received in the form of $17 \mathrm{lb}$. ingots. The $\mathrm{i}$-gots were subsequent ly homogenized. The ailoy compositions, given in Table I, were measured after homogenization. There were some slight differences in the specified amounts of each element. The ingots were then upset forged and cross-rolled at $1150^{\circ} \mathrm{C}$ into bars of 5/8 in. $x$ 3-1/8 in. cross section. Oversized tensile blanks were machined from the bars with the rolling direction as shown in Fig. 1a. The tensile blanks were heat treated prior to final machining.

\section{Heat Treating}

Oversized tensile blanks were heat treated under an inert argon atmosphere in a verticle tube ( 3 in. I.D.) furnance. The temperature was monitored via a type $K$ (Chromel-Alume 1$)$ thermocouple with a digital readout accurate to $\pm 3^{\circ} \mathrm{C}$ at $900^{\circ} \mathrm{C}$. Both thermocouple as 1 specimens were carefully suspended to hang down the center line of the vertical tube at the furnace "hot spot". (uenching was conducted in agitated 
ice brine or in some instances, agitated ice water. Air cooling was conducted by sllowing the specimens to come into contact with still room air $\left(25^{\circ} \mathrm{C}\right)$. The various heat treatments conducted in this investigation are shown in Fig. 2. A brief description of the important heat treatments is given below.

1. Intermediate Quench Treatment

${ }_{27}$ is is the customary duplex heat treatment for arriving at a standard morphology of strong phase martensite in a soft ferrite matrix. Specifically, the DFM structure is obtained by austenitizing and quenching to 100 pct. martensite followed by two-phase annealing in the $(\alpha+\gamma)$ range and then quenching. The volume fraction and ultimate carbon content of the strong phase is controlled by the annealing process. By annealing the specimens at a given temperature in the $(\alpha+\gamma)$ region, the initially quenched-in martensite provides various sites for the nuc?eation and growth of austenite to the volume fraction specified by the lever rule. ${ }^{14}$ The alloy phases present will then consist of low-carbon ferrite and high carbon austenite. Upon final quenching, the austenite transforms to martensite and the ferrite becomes dislocated due to the plastic deformation as a result of the austenite $\rightarrow$ martensite transformation strain. An additional result of the quenching process, is the carbon supersaturation in the ferrite. This carbon supersaturation amounts to around 100 and 200 times in the $\mathrm{Fe} / \mathrm{C}$ and $\mathrm{Fe} / \mathrm{C} / \mathrm{Si} / \mathrm{X}$ systems, respectively.

The austenitizing treatments, for both the experimental quaternary alloys, were performed at $1150^{\circ} \mathrm{C}$ for one hour. This temperature was selected to provide for the dissolution of the alloy carbides and 
because the $A_{3}$ line was higher due to the alloy additions. The twophase annealing temperatures varied depending upon the desired volume fraction of martensite (i.e., $20 \%$ and $40 \%$ martensite). A suitable holding time selected for annealing was ten minutes for both alloys as shown in Table IL. This annealing time affords the presence of the desired alloy carbide in the ferrite matrix as confirmed by transmission electron microscopy. The schematic in Fig. 3 portrays the customary duplex thermal treatment in conjunction with the Ferich portion of the $2.4 \mathrm{wt}$. pct. Si section of the $\mathrm{Fe} / \mathrm{C} / \mathrm{Si}$ phase diagram.

\section{Intermediate Air Cool Treatment}

This thermal treatment is analogous to the customary duplex heat treatment as shown in Fig. 2. However, this thermal treatment consists of austenitizing and initially air cooling, instead of quenching the specimens. The initial air cooled structure consists of ferrite plus other isothermal products. This has been confirmed by transmissión electrun microscopy and optical metallography. The subsequent annealing is conducted in the $(\alpha+\gamma)$ region where the austenite will heterogeneously nucleate and grow preferentially at the cementite/ferrite interfaces. 15 Upon final quenching, the austenite transforms to martensite as stated previously.

3. Continuous Air Cooling from the Austenite Region

This normalizing thermal treatment simply consists of austenitizing, then air cooling to room temperature, which produces proeutectoid ferrite and other isothermal products. 


\section{Mechanical Testing}

Tensile properties were determined using one inch gauge around tensile specimens as shown in Fig. 1b. The oversize specimens were heat treated and ground to final dimensions following ASTM specifications. 16 Approximately 0.05 inches of material was removed circumferentially about the gauge section to eliminate the possible effects of surface decarburization. The decarburization did not exceed 15 mils. The tensile tests were performed at room temperature.

The intermediate quenched and air cooled specimens were tested on an Instron machine with a cross-head speed of $0.05 \mathrm{~cm} / \mathrm{min}$. and a full scale load of $5000 \mathrm{~kg}$. The uniform elongation was continuously monitored with an optical magnifier accurate to 0.001 inches. The continuous air cooled and other heat treated specimens were tested on a M.T.S. machine with a cross-head speed of $0.05 \mathrm{in./min}$. and full scale load of 15,000 1bs. The uniform elongation in these cases was monitored by an extensometer whose output is fed into the chart drive system of the M.T.S. console. Total elongations were determined by measuring the gauge lengths after testing with an optical microscope equipped with a vernier translating stage accurate to 0.001 inches. The percent reduction in area calculations are based upon the measurement of the gauge section diameter before and after testing by vernier ealipers accurate to 0.001 inch. The values of the tensile properties :Esc:ses in Jable III are the averages of three tests and in some $\therefore E=\varepsilon . \quad \because$ 


\section{E. Metallography}

\section{Optical Metallography}

Samples for optical metallography were cut from the fractured tensile specimens behind the necked region. An abrasive cut off saw was used that utilized flood cooling to minimize specimen heating during cutting. The specimens, after mounting in Koldmount, were mechanically ground sequentially from 180 to $600 \mathrm{grit}$ wet emery paper. The specimens were cleaned in water and rotated $90^{\circ}$ between belts. Final polishing was accomplished in a one micron rotating, diamond abrasive wheel which was lubricated with kerosene. The etchants used in this metallographic investigation were 27 and $5 \%$ nital. These etchants effectively revealed the duplex microstructural constituents and prior austenite grain boundaries. The samples were examined on a Zeiss Ultraphot II microscope. The volume fraction of the martensite was determined, in part, by the standard linear intercept method. 17 2. Transmission Electron Microscopy

Bulk speciūeñs were heat treated separately from the tensile bars. Slices 0.02 inches thick were cut from the heat treated samples on an abrasive cut off saw utilizing flood cooling and a slow feed rate to minimize specimen heating. The specimens were then chemically thinned to 0.005 inches in a solution of $\mathrm{H}_{2} \mathrm{O}_{2}$ containing $4 \%$ HF at room temerature. Then 3.0 discs were spark cut and mechanically thinned to $1.0-1.5$ mils on dry emery paper (400 and $600 \mathrm{grit}$ ). The discs were cleaned in acetone and electropolished in a twin jet polishing apparatus at room temperature using a chromic-acetic polishing solution $\left(75 \mathrm{CrO}_{3}+400 \mathrm{ml} \mathrm{CH}_{3} \mathrm{COOH}+2 \mathrm{lml}\right.$ distilled $\left.\mathrm{H}_{2} \mathrm{O}\right)$. Polishing 
times varied from 3 to 5 minutes at $35-40 \mathrm{ma}$ and $30-35$ volts. The resultant foils were examined in a Jem $7 \mathrm{~A}$ cransmission electron microscope at an accelerating voltage of $100 \mathrm{kV}$. 


\section{RESULTS AND DISCUSSION}

\section{A. Microstructures}

The microstructure prior to annealing and the resultant volume fraction of the strong phase, played a major role in the duplex processing of steel. Qualitatively, the lower limit of the acceptable range of martengite volume fraction $(\mathrm{Vm})$ is restricted to the value where no strengthening of the duplex alloy occurs. The upper limit is set when the failure of the martensite immediately leads to the failure of the duplex structure. Of course, the final range of Vm will be determined from the specifications and applications for which the steel will be used. The mechanical behavior of the DFM aggregate is influenced by the size, shape, distribution and resultant connectivity of the strong phase and other metallurgical variables.

1. Intermediate Quench vs. Intermediate Air Cool

The general morphologies of the two alloys subjected to the intermediate quench and intermediate air cool thermal treatments are contrasted below. The peculiarities between the individual alloys as a consequence of each specific heat treatment will be discussed later. The martensite volume fractions considered in this investigation are $20 \%$ and $40 \%$.

The manner of distribution of the martensite is significantly different between the two heat treatments. In the intermediace quench (IQ) case, the microstructures before annealing are 1007 martensite with an average prior austenite grain size of 150 . The nucleation of austenite occurs in the initial martensite upon reheating into the two-phase region. Martensite has been shown to be favorable for 
austenite nucleation on a finer scale because of the numerous fine heterogeneities in the structure. ${ }^{1,5}$ Nucleation sites typically are the prior austenite grain boundaries, martensite lath bouncaries and carbide/ferrite interfaces. Upon quenching from the $(\alpha+\gamma)$ region, the austenite transforms to martensite as mentioned earlier. The: high density of nucleation sites results in a fine dispersion of martonsite islands within the ferrite matrix. This is evidenced in Fig. 4 by the martensite decorating the prior austenite grain and the initial martensite lath boundaries.

In the intermediate air cool (IAC) case, the microstructure prior to annealing is composed of proeutectoid ferrite plus other isolated products (i.e., pearlite) as shown in Fig. 8, 12 and 13. The sites favorable for the heterogeneous nucleation and growth of austenite in this case occurs at the carbide/ferrite interfaces. 15 The final martensite is not a fine, but a coarse distribution of massive islands embedded in the ferrite matrix. This is shown in Fig. $6 \mathrm{a}$ and $6 \mathrm{~b}$. The configuration of the martensite islands seems to depend upon the location of the initial pearlite colonies.

The general shape of the martensite depends predominantly upon where the parent austenite had nucleated and grown during the annealing process. Both the IQ and IAC treatments display a globular array of martensite particles as shown in Fig. 4 and 6, respectively. In the IQ case, however, the globular martensite decorated the prior austenite grain boundaries. Within the prior austenite grains, acicular martensite embellished the initial martensite lath boundaries. These acicular martensite particles are predominantly allotriomorphs mixed 
with a few scattered intragranular idiomorphs. ${ }^{18}$ It is evident that some of the intragranular austenite particles developed in such a manner, that once they had nucleated and grown to a critical size along the initial martensite lath boundaries, they rapidly spherodized to form globular shapes.

By comparing the morphologies of the martensite particles at the same Vm, a size correlation can be established. The globular martensite displayed along the prior austenite grain boundaries in the IQ case is the major contributor to the overall Vm. These large martensite particles at the grain boundaries arise frow the additional surface energy available at the interfaces in the austenite nucleation process. 19

In the IAC case, the globular martensite particles contribute totally to the overall Vm. These martensite particles are generolly larger than those found in the IQ ca.e. Since the martensite particles are larger, fewer are needed to produce the same desired volume fraction. It should be not:d that the annealing times and temperatures are the same in both thermal treatments for producing equal Vm. Presumably, the austenite nucleation sites afforded by the initial ferrite plus pearlite structure are fewer than in the initially martensite structure. Therefore, it is evident that the reaction kinetics in the growth of austenite mist be somewhat greater in the IAC case in order to quench-in larger martensite particles from fewer austenite sites. This is assuming that in both heat treatments the specimens reach the two-phase equilibrium at the same time. Conceivably, the higher concentration of immediately available carbon in the cementite constituent 
of the pearlite is responsible for the increased rate of the austenite nucleation and growth kinetice.

The connectivity of the strong phase plays an important $1: 01 e$ in the overall mechanical properties of the system. In essence the connectivity is the combination of the metallurgical factors of gize, shape and distribution of the martensite. Connectivity is the connecting together of the strong phase particles in the ferrite matrix. Briefly, a high degree of connectivity results in a greater chance for premature failure of the DFM aggregate since the ferrite may not be able to contribute its full ductility to the system. In the IQ case, the major sites for excessive martensite connectivity is undesirably along the prior austenite grain boundaries. In the IAC structure, connectivity is a prominent feature in the massive mastensite conglomerations. 2. Continuous Air Cooling from Austenite

The isothermal. products produced by this simple normalizing treatment are proeutectoid ferrite, pearlite and possibly bainitic ferrite as already noted in Figs. 8, 12 and 13. The application of the connectivity principle may analogously be applied to the carbon rich constituent of these normalized structures.

3. Microstructural Comparison of $\mathrm{Fe} / 0.15 \mathrm{c} / 1.45 \mathrm{si} / 0.38 \mathrm{Mo}$ vs. $\mathrm{Fe} / 0.14 \mathrm{C} / 1.45 \mathrm{Si} / 0.034 \mathrm{Nb}$

\section{a. Intermediate Quench Treatment}

The optical metallography revealed many of the important microstructural features in the duplex aggregates corresponding to this heat treatment. These features are documented in Figs. 4 and 5. Both of the molybdenum and niobium containing alloys displayed acicular 
martensite allotriomorphs predominantly within a prior $\gamma$ grain boundary. These are finely dispersed within the ferrite matrix. In addition, both alloys displayed intergranular globular martensite particles akin in size. The most striking feature exhibited by these alloys, as a consequence of the IQ treatment, was the decoration of the martensite particles along the prior austenite grain boundaries in the $40 \% \mathrm{Vm}$ case. This feature is more prominent in the molybdenum containing alloy since the martensite particles are chained together continuously along the prior austenite grain boundaries. In the niobium alloy the situation is different. Although the number of martensite particles is assumed to be the same, the particles have not ail reached a critical size necessary to provide for a continuous, strong-phase chain along the prior austenite grain boundaries. Consequently, there are regions where a continuous ferrite matrix exists. Since the prior austenite grain size is about the same for both alloys, the effect of niobium for providing grain size refinement is not evident.

Both the molybdenum and niobium alloys displayed an acicular ferrite substructure as evidenced by the example of Fig. 9. The widths of the subgrains were approximately 0.34 in both alloys. At $20 \% \mathrm{Vm}$, dramatic carbide precipitation was revealed in the ferrite regions of the molybdenum containing steels as shown in Fig. 10. The carbides of the order of $0.1 \mu$ diameter were identified to be cementite $\left(\mathrm{Fe}_{3} \mathrm{C}\right)$. Precipitation was also revealed along the ferrite/martensite interfaces. The substructural martensite was mixed with substantial twinning. The carbon content in the martensite was estimated to be 0.45 wt. pct. according to the phase diagram in Fig. 3 for a $207 \mathrm{Vm}$. No retained 
austenite was found between the martensite laths in either alloy containing $20 \% \mathrm{Vm}$. However, this does not preclude it from being present in specimens with higher Vm.

b. Intermediate Air Cool Treatment

A comparison between the molybdenum and niobium alloys at a $40 \%$ Vm shows some important contrasting microstructural features. In the molybdenum alloy, the strcag phase is 1 inked together in massive chains as shown in Fig. 6a. The niobium alloy is characterized by large martensite" island complexes dispersed irregularly throughout the ferrite matrix as displayed in Fig. 6b. The connectivity of the strong phase is more prominent in the chained structure of the molybdenum alloy than in the island complex structure of the niobium steel. Both alloys levealed large region of ferrite. Neither of the alloys, subjected to the IAC treatment, showed the prior austenite grains.

In both alloys, the substructural martensite was mixed with substantial twinning similarly as in the IQ case. This is shown in Fig. 1). Also, large acicular ferrite was noted in both alloys.

c. Continuous Air Cooling from Austenite Region

Optical metallography revealed some very contrasting wicrostructures between the molybdenum and niobium steels as a consequence of this thermal treatment. In the molybdenum steel, the strong constituent is acicular and finely dispersed throughout a continuous ferrite matrix as shown in Fig. 8a. On the other hand, the niobium sceel reveals the strong constituent to be large, interconnected, irregularly shaped and coarsely distributed throughout the ferrite matrix. This is shown in Fig. 8b. Some TEM work was done on the alloys. Pearlite, proeucectoid 
and bainitic ferrite were noted. This information is displayed in Figs. 12 and 13, respectively. Since much more molybdenum was added to the $\mathrm{Fe} / \mathrm{C} / \mathrm{Si}$ base alloy than niobium, it is not unreasonable that the hardenability in the moljbdenum steel be greacer. Hence, the strong constituent in the molybdenum alloy may be bainite and not pearlite as in the niobium steel.

\section{B. Mechanical Properties .}

\section{Overa! I Comparison of the Various Heat Treatments}

A relative correlation of mechanical proparties has been established between the various heat treatments without regards to the alloy compositions. By examining the corresponding tensile data in Table III, the specimens subjected to the IQ treatment displayed improved total and uniform elongations over those of the IAC process. Total and uniform elongations are defined as elongations to tensile failure and necking, respectively. Typical total elongations ( $e_{T}$ ) range from 12-20\% in the IQ case with the uniform elongations ( $e_{u}$ ) on the order of 9-14\%. In the IAC case, the $e_{T}$ ranges from 7-117 with the $e_{u}$ extending from 7-10\%, The examination of these elongation values reveals in the IAC case that $e_{T}$ and $e_{u}$ are about the same in magnitude (i.e., $e_{T} \approx e_{u}$ ). In other words, tensile failure occurred near the ultimate tensile strength with little specimen necking. In the IQ case, the $e_{T}$ and $e_{u}$ differed significantly (i.e., $\left.e_{T}>e_{u}\right)$. This is an important engineering consideration since it is undesirable For structures or machine parts to fail near the ultimate tensile gtrergth of the material. The strength vs. elongation data is plotted in Figs. 14-17. 
The ultimate tensile strength (U.T.S.) of the tensile specimens varied according to the transformation path of the duplex treatment i.e., with the microstructure. The U.T.S. increased with higher two-phase annealing temperatures ( $V_{w}$ is a function of the annealing temperature). Typical U.T.S. values obtained, ranged from 120-130 KSI and 111-138 XSI as a consequence of the IQ and IAC treatments, respectively. The latter was more sensitive to the two-phase annealing temperature. This means that control of the U.T.S. would be more difficult from a practical or industrial point of view.

The yield strergth (Y.S.) of the tensile specimens ranged from 76-90 KSI for bs:h the IQ and IAC treatments. In addition, the Y.S. rended to decrease with increasing specimen elongation. This suggests that a similar mechanism governed the Y.S. in both of the duplex heat treatments and will be discussed later.

The continuous air cooling treatment exhibited superior $e_{T}$ and $e_{u}$ values. The $e_{T}$ and $e_{u}$ values ranged from $32-33 \%$ and $18-20 \%$, respectively. The U.T.S. values extended from 84-91 KSI. The Y.S. values ranged from 55-69 KSI.

2. Mechanical Property Comparison of Fe/0.15 C/1.45 Si/0.38 Mo vs. $\mathrm{Fe} / 0.14 \mathrm{C} / 1.45 \mathrm{Si} / 0.034 \mathrm{Nb}$

The mechanical property comparison between the molybdenum and niobium alloys is considered below in regards to the type of heat treatment and the corresponding two-phase ann-aling temperature where appropriate. 


\section{a. Intermediate Quench Treatment}

The niobium alloy displayed improved elongation ductility at comparable U.T.S. and Y.S. values over the molybderum steel. This is shown in Fig. 18. The elongation ductility of the molybdenum steel is more sensitive to annealing temperature variations than in the niobium alloy.

\section{b. In ermediate Air Cool Treatment}

The niobium alloy displayed improved elongation ductility over the molybdenum alloy as shown in Fig. 19. The value of the Y.S. levels is similar in both duplex steels. The U.T.S. values of the molybdenum alloy are more sensitive to the anrealing temperature variations.

c. Continuous Air Cooling from the Austenite Region

The molybdenum steel shown in Table III has improved $e_{T}$, $e_{u}$ and higher U.T.S. and Y.S. values than the niobium alloy.

\section{Mechanical Property/Microstructure Correlations}

\section{Strengthening Mechanisms}

A quantitative description of the mechanical behavior of the DFM steels considered in this investigation requires a knowledge of the specific mechanisms by which slip can be transmitted across a given microstructural barrier. The available slip distance in the ferrite is the most important variable in determining the strength which is governed by the size, shape, distribution and resultant connectivity of the second phase, as well as the submicroscopic alloy carbide precipitation in the ferrite. Consequently, the nature of the slip barriers is important. 
Originally, strengthening of the DFM aggregate was approximated by the fiber reinforced composite model $2,6,20-22$ where the barriers to dislocation motion are the strong phase/matrix interfaces. The theoretical strength of such a composice is given by:

$$
\sigma_{c}=\sigma_{f}\left(1-V_{m}\right)+\sigma_{m} V_{m}
$$

where: $\sigma_{c}=$ ultimate composite strength of the duplex alloy $\sigma_{m}=$ intrinsic strength of the martensite $\sigma_{f}=$ intrinsic stress in the ferrite at the ultimate tensile strain of the martensite om $=$ volume fraction of the martensite $\left(1-V_{m}\right)=$ volume fraction of the constituent ferrite phase. The derivation of $\sigma_{c}$ is based solely upon the fiber loading concept and not on any actual dislocation mechanism. This is because the fiber model describes the extreme case where the strong phase particles are continuous and unidirectionally aligned in the direction of the applied flow stress. These are clearly not the actual conditions in these duplex alloys. Hence, any attempt to quantitatively relate Eq. (1) would be empirical only. ${ }^{4}$

The presence of alloy carbides in the ferrite matrix prompts a discussion of a dispersion strengthening mechanism. The barriers to slip or dislocation motion are considered to be point obstacles. The mechanism whereby the dislocations encounter and bypass the point obstacles is described by the orowan mechanism. ${ }^{23}$ The flow stress required to bypass a point obstacle is given by: 


$$
\tau=\tau_{0}+\alpha \frac{G b}{\lambda \mathbf{p}}
$$

where: $\tau_{0}=$ flow stress of the ferrite matrix

$\alpha$ geometrical constant depending on the particle shape and distribution

G = shear modulus of the alloy

$b=$ Burgers vector of the glide dislocations

$\lambda_{p}=$ average interparticle spacing.

The Orowan strengthening mechanism is appreciable in these alloys since the interparticle spacings are less than a few microns. 24

It should be noted that if the particles are spaced at distances less than the mean free dislocation slip length an enhanced strengthening of the matrix will result. Hence the mechanical properties will no longer be of the single phase matrix.

Al though it is well established that Eqs. (1) and (2) can provide quantitative predictions of strengthening for the respective conditions, there is less known about the mechanism which governs the flow properties of the transitional system such as diplayed by the duplex alioys in this investigation. Other transitional cases of technological interest are such duplex alloys as ferrite-pearlite and spheroidite structures. 5 The majority of the studies on the plastic deformation rely on experimental observations due to the difficulty in theoretical analysis arising from geometrical complexities. 25,26

\section{Qualitative Relationships}

It is instructive to briefly discuss the influence of the constituent phases on the mechanical behavior of an $\mathrm{Fe} / \mathrm{C} / \mathrm{Si}$ steel subjected to 
the customary duplex processing treatment. It is generally accepted that the strength of the DFM aggregate is controlled by the $\mathrm{Vm}$ such that if the Vm increases, the strength increases. Since the strong phase is the load carrying constituent of the duplex composite, the U.T.S. is directly influenced by Vm. The Y.S. is governed by the flow stress of the ferrite when the ferrite forms a continuous matrix which is, in turn, influenced by the $V_{m}$. A higher $V_{m}$ means a correspondingly lower volume fraction of the ductile constituent ferrite. Increasing the barriers to dislocation motion within the ferrite results in a higher required stress for the system to change from elastic to plastic deformation modes. Normally, the ferrite flow stress is increased primarily by higher $V_{m}$ since there are more ferrite/martensite interfaces to inhibit dislocation motion. Other factors which influence the flow stress are subgrains and alloy carbide precipitation in the ferrite matrix.

This investigation reaffirms that the U.T.S. is directly proportional to the Vm. This is illustrated in Fig. 20. The U.T.S. of both alloys, as a result of the IQ and IAC treatments, increases as the Vm increased. Therefore, it is evident that the martensite is the major contributor to the U.T.S. of the system.

The Y.S., however, tends to decrease with a higher $V_{m}$ as shown in Fig. 20. Specifically, the Vm at $20 \%$ results in a higher Y.S. than at $40 \%$. This result contradicts the customary influence of the martensite on the Y.S. of a DFM steel. The explanation to this unusual behavior can be given as follows: It is evident that other barriers to dislocation motion operated besides those due to the ferrite/martensite 
interfaces, such as the alloy carbide precipitation in the ferrite matrix. According to the phase diagram in Pig. 3, correspondingly lower $(\alpha+\gamma)$ arnealing cemperatures, result in a higher carbon supersaturation in the ferrite. The specimens containing a $20 \%$ were annealed at a lower temperature than those containing a $40 \% \mathrm{Vm}$. If the excess arbon in the territe is used in the alloy carbide precipitation, it is probable that specimens annealed to obtain a $20 \%$ VII would have more alloy catbide precipitation resulting in a higher Y.S. This behavior is noted in the molybdenum and niobium alloys irrespective of the duplex thermal treatment.

The carbide precipitation drastically affects the elongation cuctilicy. Figure 21 displays the total and uniform elongations of the alioys as a function of the Vm for the duplex treatments considered. The tensile specimens containing a $20 \% \mathrm{Vm}$ displayed poorer elongation values than those at the higher $\mathrm{Vm}$. Although increasing the Vm reduces the volume fraction of the soft ferrite phase, the influence of the carbide precipitation in the ferrite is thought to be the critical factor affecting the ductility. Possibly, the substructural affect of the twinned martensite was also responsible for the poorer elongation properties. Hence, improving the elongation ductility of the duplex steels through carbide precipitation in the ferrite is not realized for the alloy systems investigated.

The carbide precipitation in the ferrite matrix reduced the specimen U.T.S./Y.S. ratio. This is illustrated in Fig. 20 by the smaller distance between the corresponding U.T.S. and Y.S. values 
as the Vm decreases. Improved U.T.S./Y.S. ratios are noted in both alloys as a consequence of the IQ treatment.

As a result of the IQ treatment, the niobium steel displayed the best combination of mechanical properties. The microstructure of this DFM aggregate displayed more continuous regions in the ferrite matrix.

\section{Comparison To Some Commercially Available HSLA And Other DFM Steels}

The strength vs. elongation data from some of the commercially available Republic HSLA steels was plotted in Fig. 22. The $27 \mathrm{Si}$ duplex steel designed by $\mathrm{Koo}^{5}$ is displayed showing its superior strength and elongation ductility. The properties of these selected steels are compared to the molybdenum and niobium specimens which were subjecte't to the IQ treatment. Although both alloys showed superior strengths, only the niobium steel displayed commercially comparable elongation ductility. However, the final selection of an appropriate DFM steel is determined by the required mechanical properties necessary Lr the particular application in which the steel will be used. 


\section{CONCLUSION}

Based upon the investigation and characterization of the microduplex alloys with carbide forming elements in this research, the following conclusions are made:

(1) Dispersion hardening as a secondary strengthening mechanism has an important influence on the overall mechanical properties of the system.

(2) If carbides are present as shown to be the case in this investigation, the influence of martensite for controlling the overall mechanical properties of the system, is reduced. Although the Vm controls the U.T.S., the Y.S. and elongation ductility are more influenced by the flow properties of the ferrite arising from the dispersion of alloy carbides rather than by increasing the ferrite/martensite interfaces.

(3) The need for high purity in the duplex processing of lowcarbon low-alloy steels is reaffirmed if the ductility property is the primary concern. It is noted that alloy carbide precipitation in the ferrite matrix significantly reduces the elongation ductility, the U.T.S./Y.S. ratio and increases the Y.S. of the system.

(4) The connectivity of the strong phase is influenced by the size, shape and distribution of the martensite particles. It appears that the connectivity of the martensite particles is an important factor contributing to the premature failure of the DFM composite where the ferrite is not able to provide itg full ductility to the system. 
(5) The IQ route provided strength and elongation ductility combinations which were improved over those obtained by the IAC process. 


\section{ACKNOWLEDGYENTS}

I wish to express my deep appreciation to Professor Gareth Thomas for his encouragement and guidance throughout the course of this investigation. I would like to thank my friend J. Y. Koo for his invaluable assistance and encouragement. I am grateful to B. V. Rao for his critical review of this material. A special thanks is to be extended to my wife Marilyn for her love and understanding. Finally, I am greatly indebted to our Lord Jesus Christ for His continual love and support.

This work was supported by the Materials and Molecular Research Division of the U.S. Department of Energy under contract W-7405-ENG-48. 


\section{REFERENCES}

1. J. Y. Koo and G. Thomas, Mat. Sci. and Engr., 24, 187 (1976).

2. J. Y. Koo and G. Thomas, Met. Trans", 8A, 525 (1977).

3. J. Y. Koo, M. S. Thesis, University of California, Berkeley, LBL-3587, Feb. (1975).

4. M. J. Young, M. S. Thesis, University of California, Berkeley, LBL-6620, Nov. (1977).

5. J. Y. Koo, Ph.D. Thesis, University of California, Berkeley, LBL-6657, Aug. (1977). (See also J. Y. Koo and G. Thomas: Symposium on HSLA Formable Steels: AIME in press, LEL-6995).

6. S. Hayami and T. Furukawa, Micro Alloying '75, Symposium on High Strength, Low Alloy Steels, Products and Process, p. 78, Washington D.C. $(1975)$.

7. R. L. Cairns and J. A. Charles, JISI, 205, 1044 (1967).

8. R. A. Grange, Proceedings of the 2nd Int' 1 . Conf. on the Strength of Metals and Alloys, p. 861, ASM, Pacific Grove (1970).

9. K. Araki, K. Nakaoka, M. Abe, and N. Ohashi, 9th Biennial Conference of IDDRG Research Group Proceedings, 39 (1976).

10. B. Harris, Composites, p. 152 July (1972).

11. I. L. Mongford, Met. Rev. 114, 12, 49 (1967).

12. G. Thomas, Battelle Conf. on Fundamental Aspects of Structural Alloy Design, Richland, Wash., LBL-4175 (1975).

13. Baume ister, Mark's Standard Handbook for Mechanical Engineers, McGraw-Hi11, Inc. (1967).

14. A. G. Guy, Introduction to Material Science, McGraw-Hill, Inc. p. $66(1972)$. 
15. A. G. Guy and J. J. Hren, Elements of Physical Metallurgy, AddisonWesley Co., Mass., p. 406 (1974).

16. Annual Book of ASTM Standards, Designation E8-69, p. 196 (1973).

17. E. E. Underwood, Metals Engr. Quart,, 1, 70 (1961).

18. H. I. Aaronson, Decomposition of Austenite by Diffusional Processes,

V. F. Zackay and H. I. Aaronson, eds., Interscience, N.Y., P. 387 (1962).

19. A. G. Guy and J. J. Hren, op cit., p. 420.

20. B. Karlsson and G. Lindén, Mat. Sci. and Engr. 17, 209 (1975).

21. S. D. Antolovich, A. Saxeria, and G. R. Chanani, Met. Trans., $\underline{5}, 623(1974)$.

22. P. L. Manganon, Jr. and G. Thomas, Met. Trans., 1, 1577 (1970).

23. E. Orowan, Nature, 149, 643 (1942).

24. A. Kelly, Met. Trans., 3, 2313 (1972).

25. V. R. Riley, J. Composite Materials, 2, 436 (1968).

26. G. C. Sih, E. P. Chen, and S. H. Huang, Engr. Fracture Mechanics, 6. $343(1974)$. 


$$
-32-
$$

Table I: Alloy compositions.

\begin{tabular}{llllll}
\hline $\begin{array}{l}\text { Alloy } \\
\text { Designation }\end{array}$ & $\begin{array}{c}\text { Fe } \\
\text { (elements given in wt. pct.) }\end{array}$ & $\begin{array}{l}\mathrm{C} \\
\mathrm{Nb}\end{array}$ & Mo \\
\hline $\mathrm{A}$ & $\mathrm{Bal}$ & 0.15 & 1.45 & - & 0.38 \\
$\mathrm{C}$ & $\mathrm{Bal}$ & 0.4 & 1.45 & 0.034 &.- \\
\hline
\end{tabular}


Table II: Annealing temperatures in the $(\alpha+\gamma)$ range with a ten minute holding time.

\begin{tabular}{|c|c|c|c|}
\hline \multirow[t]{2}{*}{ Heat Treatment } & \multirow[t]{2}{*}{ * Martensite } & \multicolumn{2}{|c|}{ Annealing Temperatures $\left({ }^{\circ} \mathrm{C}\right)$} \\
\hline & & molybdenum alloy & niobium alloy \\
\hline $\begin{array}{l}\text { Intermediate } \\
\text { Quench }\end{array}$ & $\begin{array}{l}40 \\
20\end{array}$ & $\begin{array}{l}840 \\
788\end{array}$ & $\begin{array}{l}840 \\
788\end{array}$ \\
\hline $\begin{array}{l}\text { Intermediate } \\
\text { Air Cool }\end{array}$ & $\begin{array}{l}40 \\
20\end{array}$ & $\begin{array}{l}840 \\
788\end{array}$ & $\begin{array}{l}840 \\
788\end{array}$ \\
\hline $\begin{array}{l}\text { Direct Annealing } \\
\text { treatments: }\end{array}$ & & & \\
\hline $\begin{array}{l}\text { Continuous Air Cool } \\
\text { from }(\alpha+\gamma)\end{array}$ & & 788 & 788 \\
\hline $\begin{array}{l}\text { Quenching from } \\
(\alpha+\gamma)\end{array}$ & 20 & 788 & 788 \\
\hline
\end{tabular}


Table III: Tenoile teot oumary.

\begin{tabular}{|c|c|c|c|c|c|c|c|c|}
\hline $\begin{array}{l}\text { Specieen } \\
\text { Designation }\end{array}$ & $\begin{array}{l}\text { Heat } \\
\text { Treateent }\end{array}$ & $\begin{array}{l}50 \\
(x)\end{array}$ & $\begin{array}{l}\text { U.T.S. } \\
\text { (XSI) }\end{array}$ & $\begin{array}{l}\text { y.s. } \\
\text { (xsi) }\end{array}$ & $\stackrel{1}{(2)}$ & $\frac{u}{(2)}$ & (z) & U.T.S./Y.S. \\
\hline
\end{tabular}

DUPLEX TREATENTS:

\begin{tabular}{|c|c|c|c|c|c|c|c|c|}
\hline $\begin{array}{l}\text { All } \\
\text { C11 } \\
\text { B12 } \\
\text { C12 }\end{array}$ & $\begin{array}{l}\text { Internediate } \\
\text { Quench }\end{array}$ & $\begin{array}{l}40 \\
40 \\
20 \\
20\end{array}$ & $\begin{array}{l}129.1 \\
130.2 \\
126.2 \\
121.0\end{array}$ & $\begin{array}{l}76.6 \\
80.9 \\
87.8 \\
88.4\end{array}$ & $\begin{array}{l}16.3 \\
19.5 \\
12.3 \\
19.7\end{array}$ & $\begin{array}{l}12.2 \\
13.9 \\
10.0 \\
12.9\end{array}$ & $\begin{array}{l}23.7 \\
33.1 \\
21.2 \\
46.1\end{array}$ & $\begin{array}{l}1.7 \\
1.6 \\
1.4 \\
1.4\end{array}$ \\
\hline $\begin{array}{l}A 13 \\
C 13 \\
A 33 \\
C 33\end{array}$ & $\begin{array}{l}\text { Intereediate } \\
\text {-ir cool }\end{array}$ & $\begin{array}{l}40 \\
40 \\
20 \\
20\end{array}$ & $\begin{array}{l}137.9 \\
134.7 \\
111.3 \\
122.6\end{array}$ & $\begin{array}{l}89.8 \\
85.2 \\
81.5 \\
87.7\end{array}$ & $\begin{array}{r}7.5 \\
10.8 \\
7.7 \\
7.7\end{array}$ & $\begin{array}{l}7.0 \\
9.3 \\
7.3 \\
7.4\end{array}$ & $\begin{array}{r}11.4 \\
20.3 \\
0.0 \\
7.5\end{array}$ & $\begin{array}{l}1.5 \\
1.6 \\
1.4 \\
1.4\end{array}$ \\
\hline
\end{tabular}

MORMLIZING TREATREMT:

$\begin{array}{llllllll}\text { A31 } & \text { continuout ir } & 90.8 & 68.6 & 33.4 & 19.5 & 63.5 & 1.3 \\ \text { C31 } & \text { cooling from } & 84.8 & 55.1 & 33.0 & 18.0 & 56.7 & 1.5 \\ (Y) & & & & \end{array}$

DIRECT ANHEALIMG TREATERTS:

\begin{tabular}{|c|c|c|c|c|c|c|c|c|}
\hline $\begin{array}{l}\text { A } 32 \\
\text { C } 32\end{array}$ & $\begin{array}{l}\text { concinuout air } \\
\text { cooling from } \\
(a+y)\end{array}$ & & $\begin{array}{l}78.3 \\
76.6\end{array}$ & $\begin{array}{l}54.3 \\
53.0\end{array}$ & $\begin{array}{l}34.1 \\
46.10\end{array}$ & $\begin{array}{l}20.8 \\
22.3\end{array}$ & $\begin{array}{l}68.9 \\
65.8\end{array}$ & $\begin{array}{l}1.4 \\
1.4\end{array}$ \\
\hline $\begin{array}{l}A 42 \\
C 42\end{array}$ & $\begin{array}{l}\text { Quenching } \\
\text { from }(\alpha+y)\end{array}$ & $\begin{array}{l}20 \\
20\end{array}$ & $\begin{array}{l}135.8 \\
133.7\end{array}$ & $\begin{array}{l}77.8 \\
79.1\end{array}$ & $\begin{array}{l}12.5 \\
16.9\end{array}$ & $\begin{array}{r}9.5 \\
13.4\end{array}$ & $\begin{array}{l}29.8 \\
40.9\end{array}$ & $\begin{array}{l}1.7 \\
1.7\end{array}$ \\
\hline
\end{tabular}




\section{FIGURE CAPTIONS}

Fig. 1. (a) Schematic diagram showing the orientation of a tensile specimen in the hot rolled bar. (b) sketch sf a tensile bar specimen.

Fig. 2. Schematic representation of the various heat treatments conducted in this invesigation to control the final microstructure.

Fig. 3. Schematic of the intermediate quench heat treatment in conjunction with the Fe-rich portion of the 2.4 wt. pct. section of the $\mathrm{Fe} / \mathrm{C} / \mathrm{Si}$ phase diagram.

Fig. 4. Optical micrographs of the DFM structure with $40 \%$ martensite developed by the intermediate quench treatment. (a) molybdenum alloy and (b) niobium alloy.

Fig. 5. Optical micrographs of the DFM structure with $20 \%$ martensite developed by the intermediate quench treatment. (a) molybdenum alloy and (b) niobium alloy.

Fig. 6. Optical micrographs of the DFU structure with 407 martensite developed by the intermediate air cool treatment. (a) molybdenum alloy and (b) niobium alloy.

Fig. 7. Optical micrographs of the DFM structure with 207 martensite developed by the intermediate air cool treatment. (a) molybdenum alloy and (b) niobium alloy.

Fig. 8. Optical micrographs showing the proeutectoid ferrite plus other isothermal products as consequence of continuously air cooling from the austenite region. (a) molybdenum alloy and (b) niobium alloy. 
Fig. 9. This bright field micrograph of the molybdenum alloy shows a martengite packet in a lath ferrite matrix. This specimen contains 207 martensite as a result of the intermediate quench treatment. The packet substructure consists of twinned and lath martensite.

Fig. 10. This TEM micrograph of the molybdenum steel shows the moly carbides embedded in the lath ferrite matrix. This specimen was subjected to the intermediate quench treatment and contains $20 \%$ martensite.

Fig. 11. This bright field micrograph of the niobium alloy contains a martensite packet surrounded by a ferrite matrix. The packet substructure consists of a mixture of twinned and lath martensite. This specimen was subjected to the intermediate air cool treatment and contains $20 \%$ martensite.

Fig. 12. The niobium alloy which was continuously air cooled from the austenite region contains pearlite and ferrite as evidenced by this TEM micrograph.

Fig. 13. These bright field micrographs are from the molybdenum alloy which was continuously air cooled from the austenite region. (a) proeutectoid ferrite and (b) bainitic ferrite.

Fig. 14. Strength vs. total elongation is plotted for the DFM molybdenum alloys as a result of the intermediate quench and intermediate air cool heat treatments.

Fig. 15. Strength vs. uniform elongation is plotted for the DFH molybdenum alloys as a result of the intermediate quench and intermediate air cool treatments. 
Fig. 16. Strength vs. total elongation is plotted for the DRM niobium alloys as a result of the intermediate quench and intermediate air cool heat treatmente.

Fig. 17. Strength vg. uniform elongation is plotted for the DFM niobium alloys as a result of the intermediate quench and intermediate air cool treatments.

Fig. 18. In this figure, the molybdenum and niobium alloys are compared in regards to their strength vs. total elongation. These specimens were subjected to the intermediate quench treatment.

Fig. 19. In this figure, the molybdenum and niobium alloys are compared in regards to their strength vs. total elongation. These specimens were subjected to the intermediate air cool treatment.

Fig. 20. The strength vs. $Z$ martensite for the molybdenum and niobium alloys as a result of either the intermediate quench or intermediate air cool treatment are noted in this figure.

Fig. 21. The $Z$ elongation as a function of $Z$ martensite is shown for both alloys. The duplex heat treatments to which these alloys were subjected are noted in the figure.

Fig. 22. This figure illustrates a comparison of strength vs. totsl elongation between some of the commercially available HSLA steels and selected DFM alloys. 


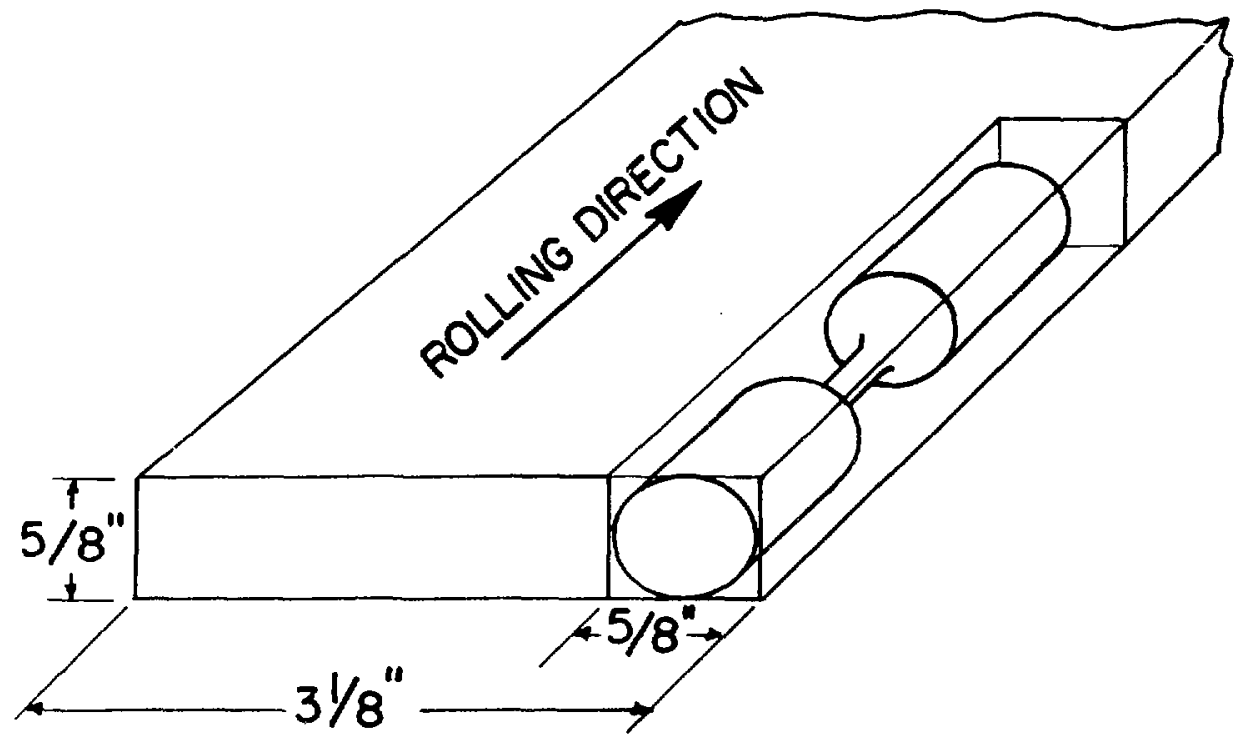

(a)

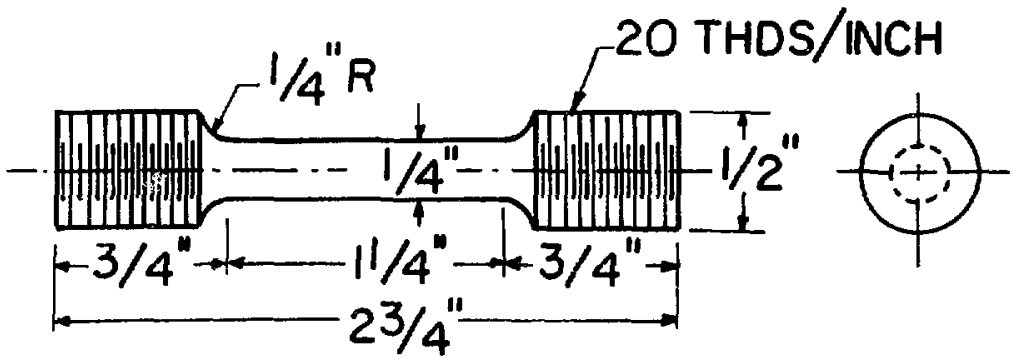

(b)

X BL 789-5837

Fig. 1 


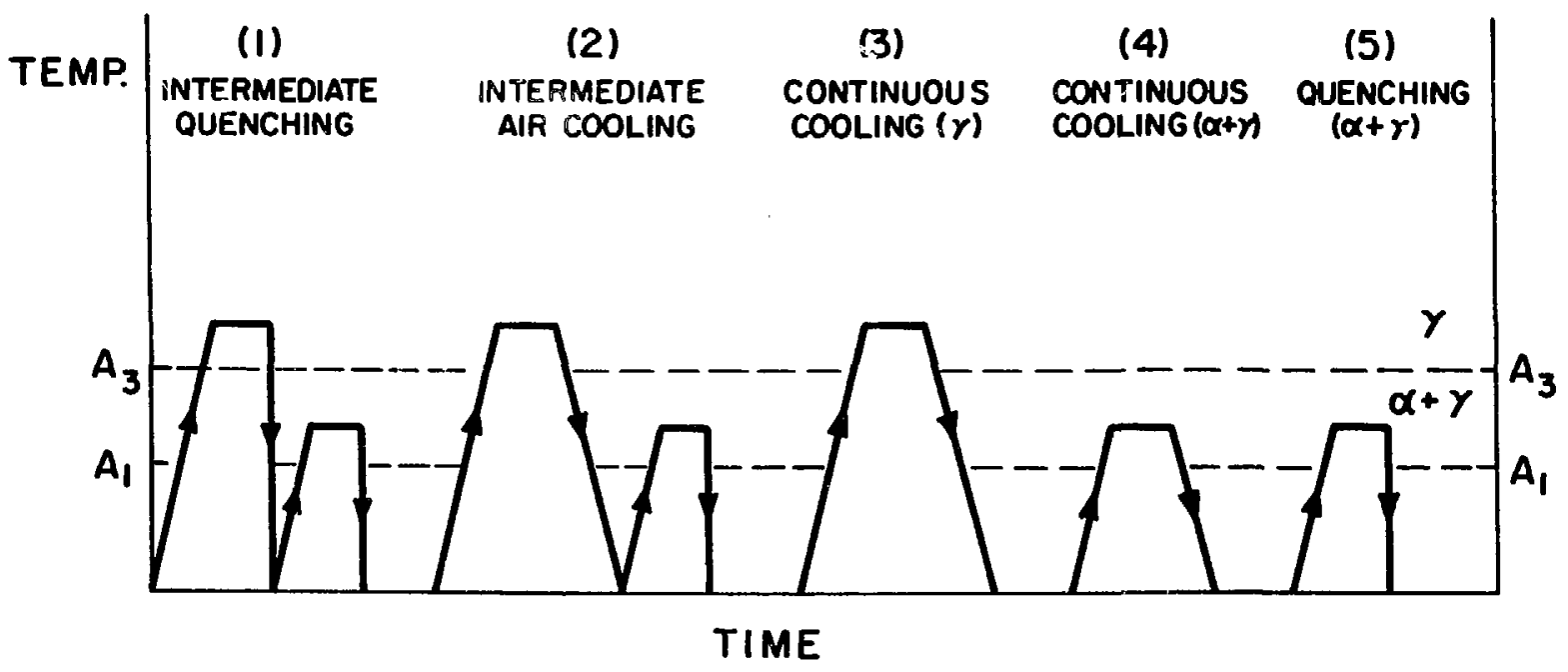

Fig. 2 
Fe-RICH PORTION OF THE

2.4 WT. \% SECTION OF

$\mathrm{Fe}-\mathrm{SI}$-C PHASE DIAGRAM

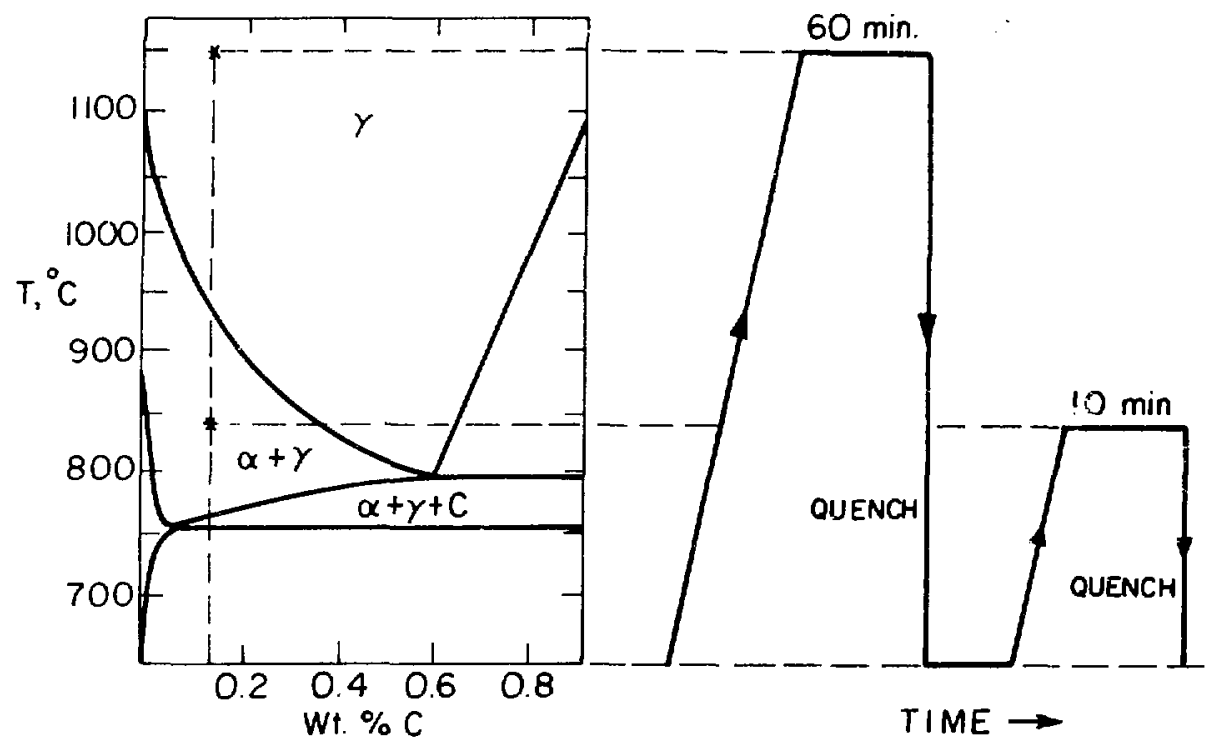

XBL 789-5836

Fig. 3 

(2)

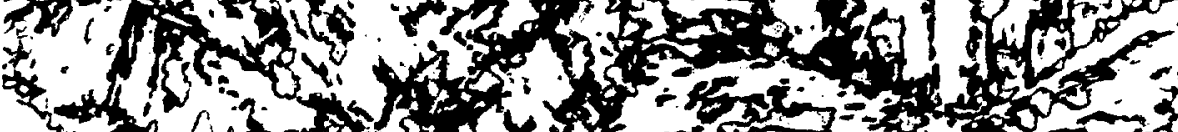

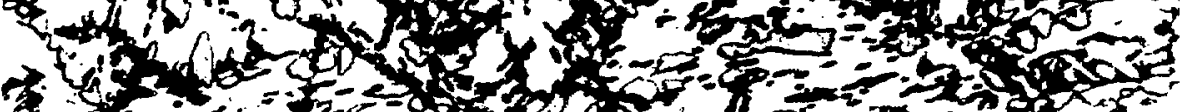

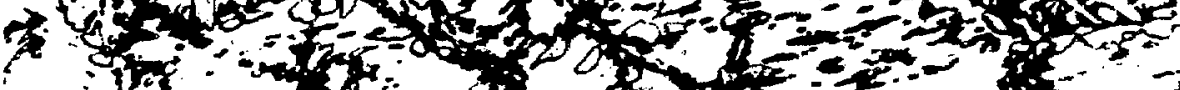
.

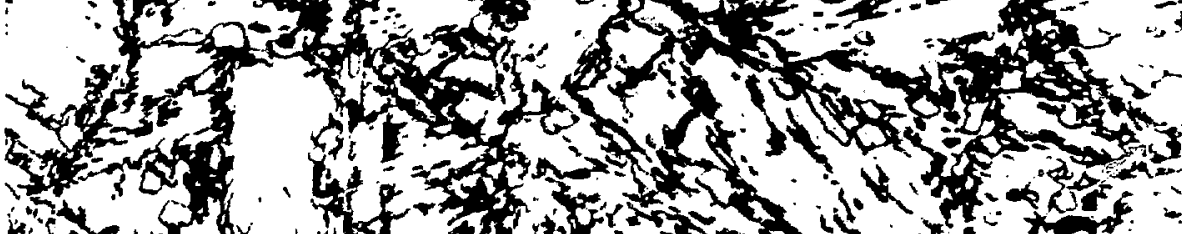

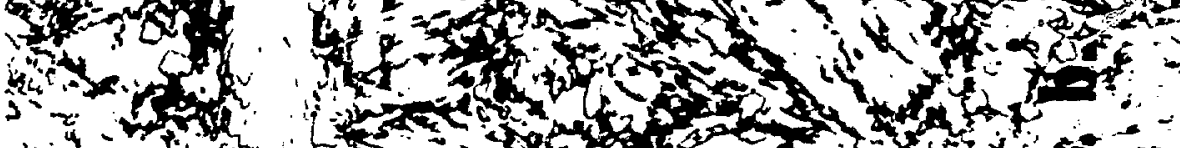
$\therefore$.

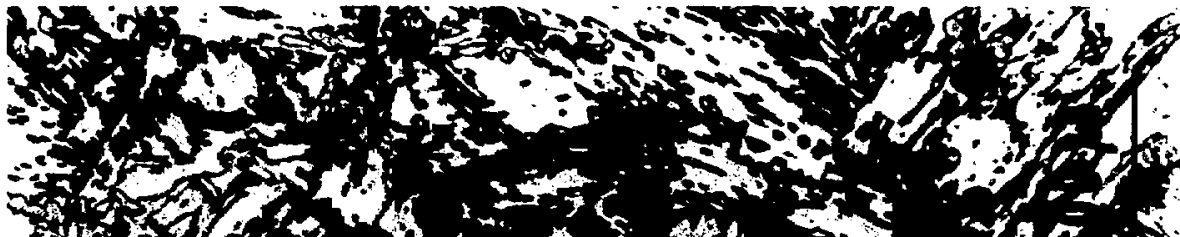

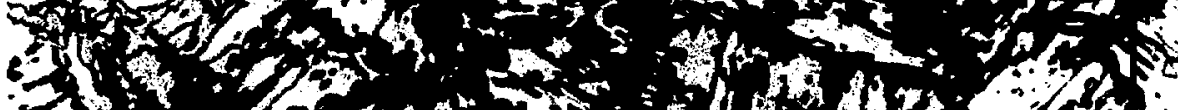

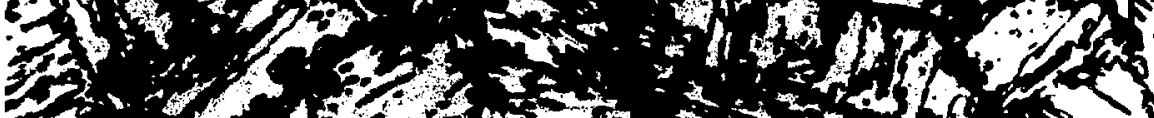
$-10,0 \leqslant 30$

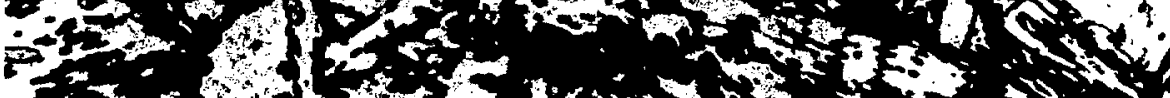

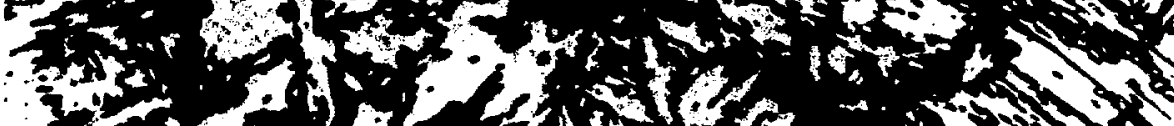
$3=12$ low

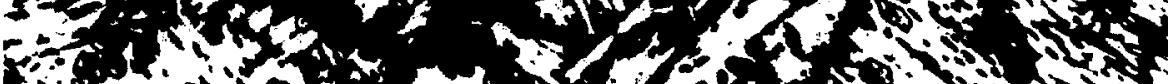

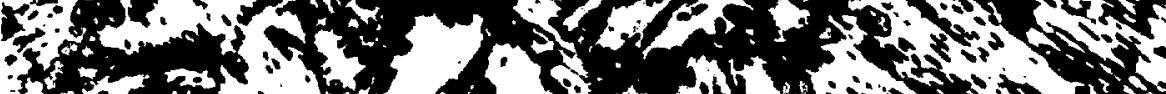

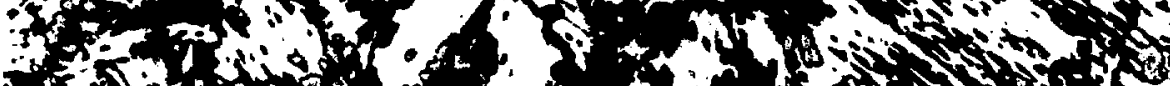
$x+4+1,12$

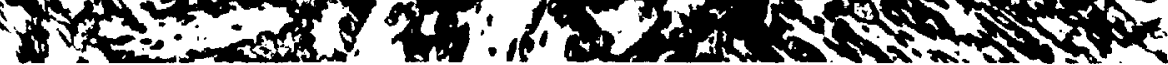




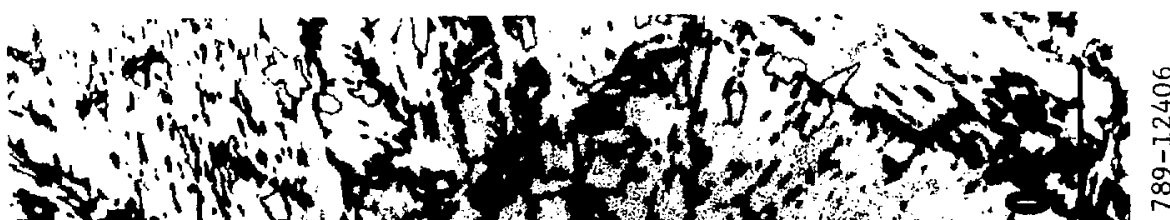

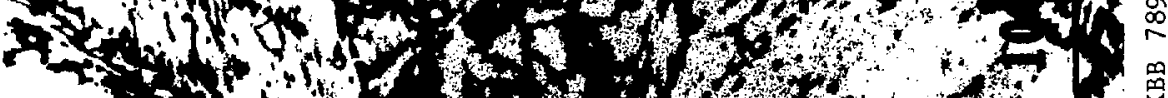

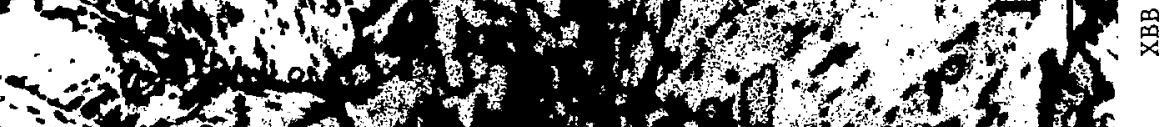

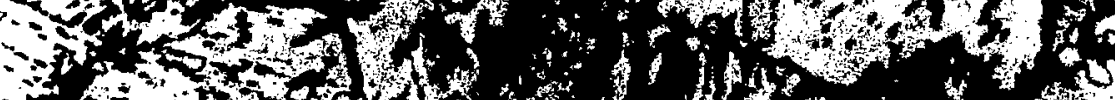

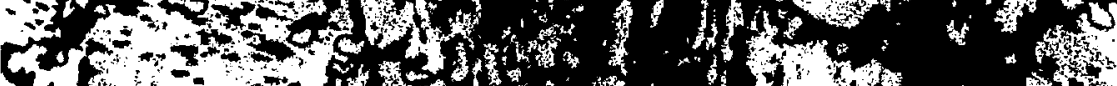
nt

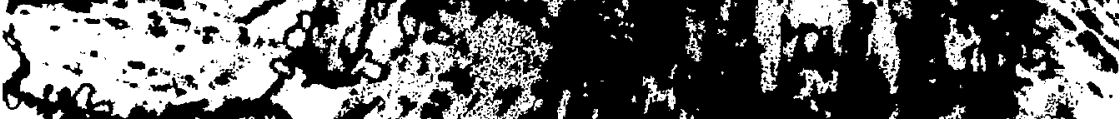

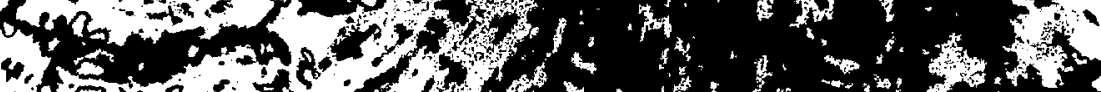

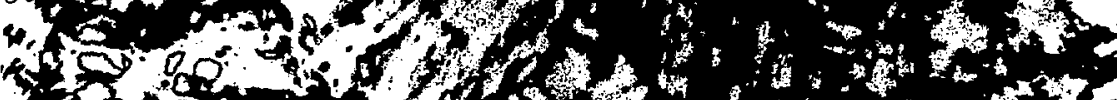

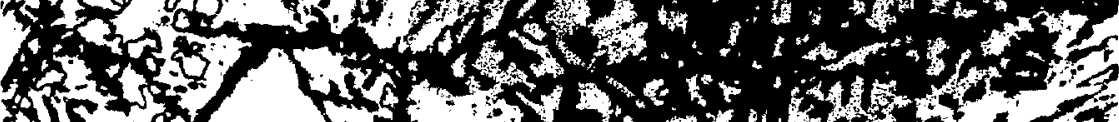

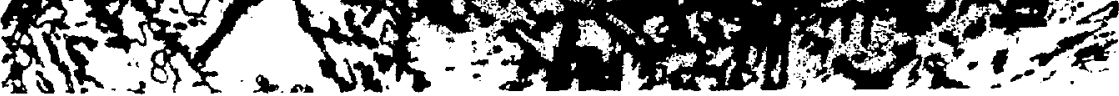

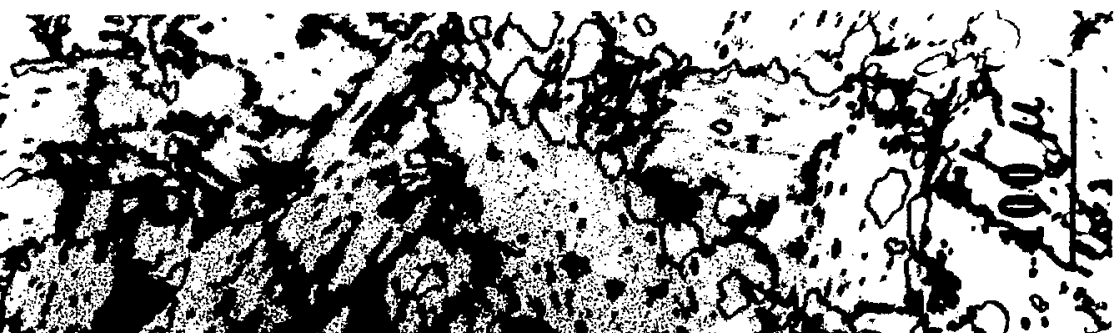

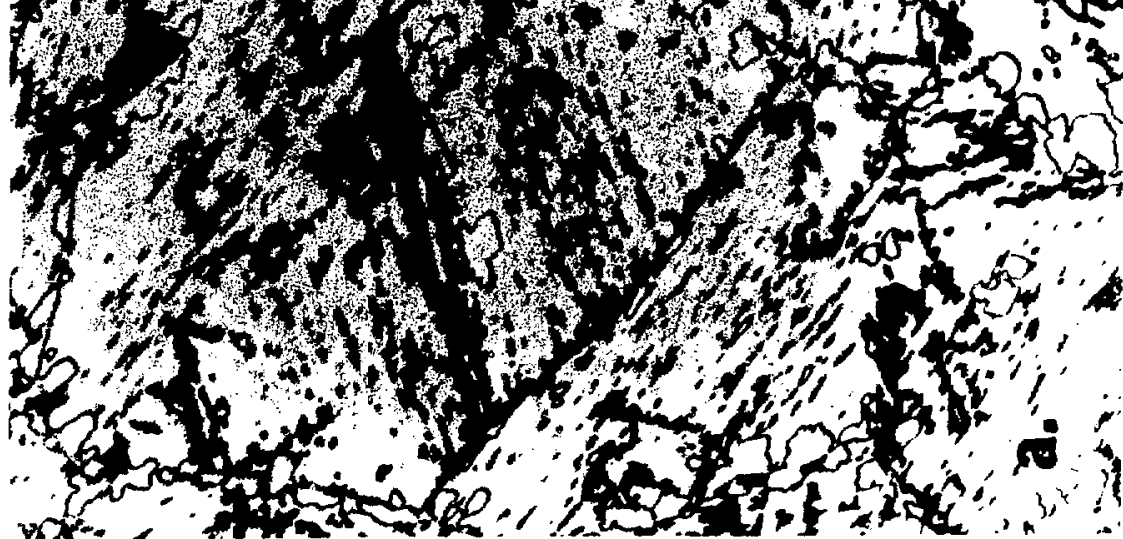




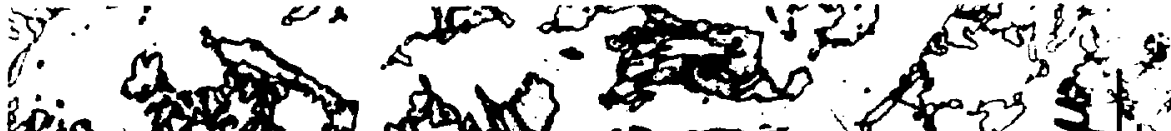

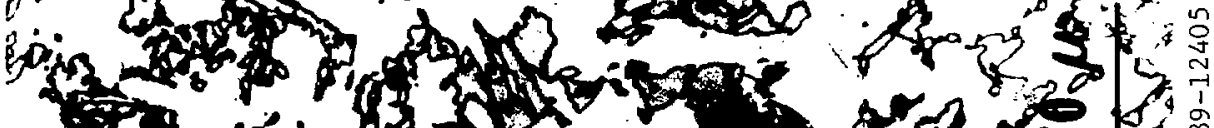
:3.

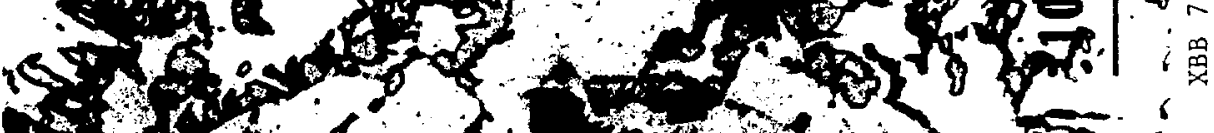
g.t.

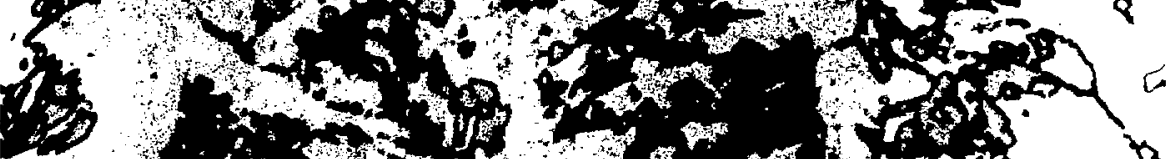

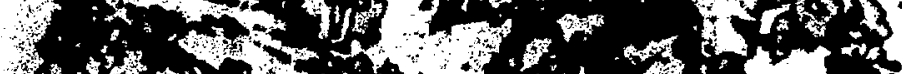

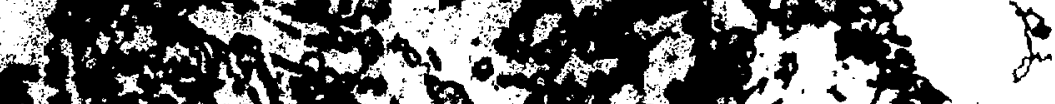

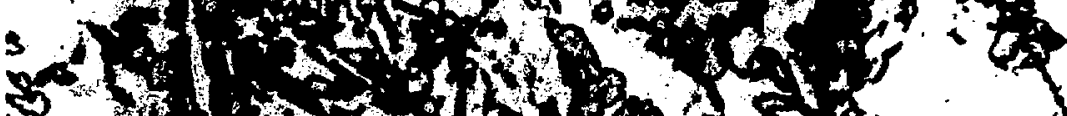

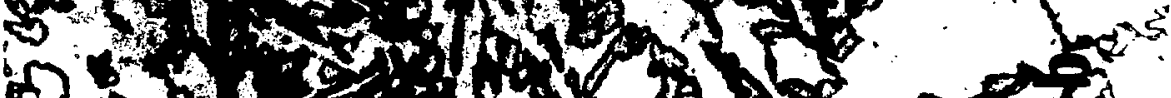

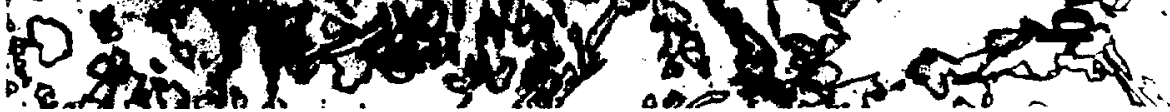

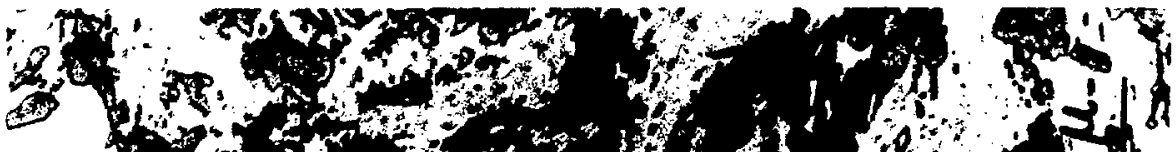

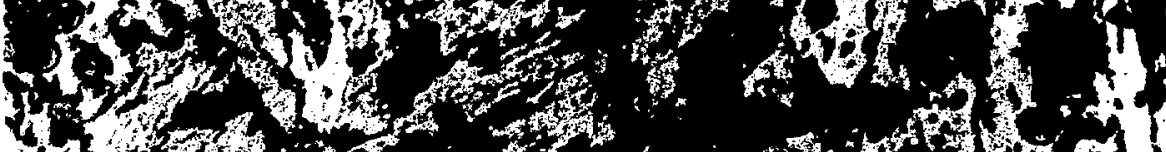

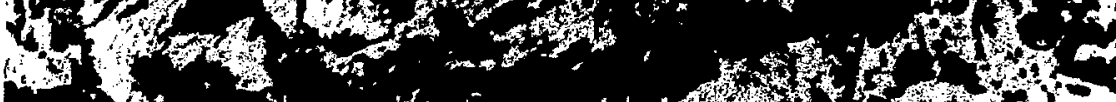

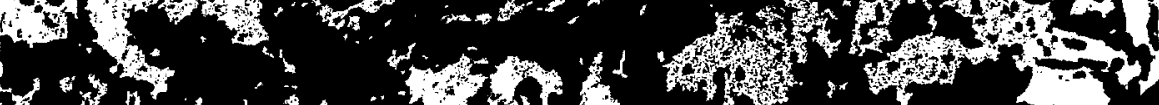

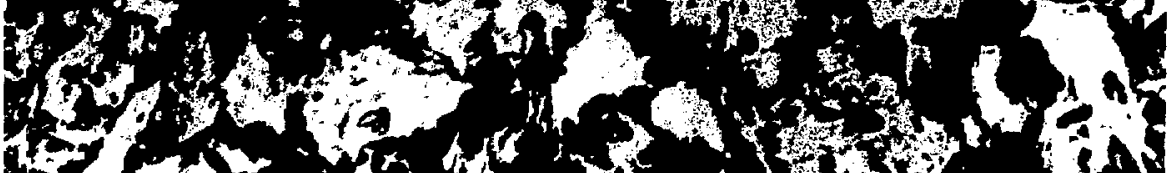

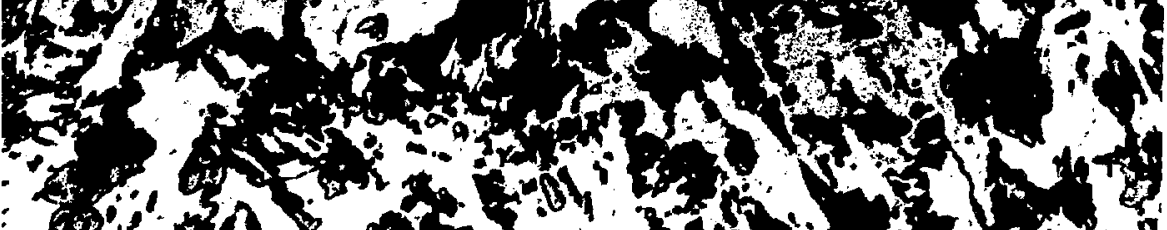

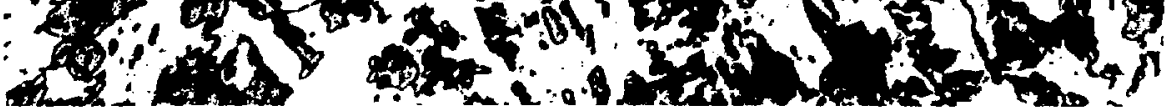




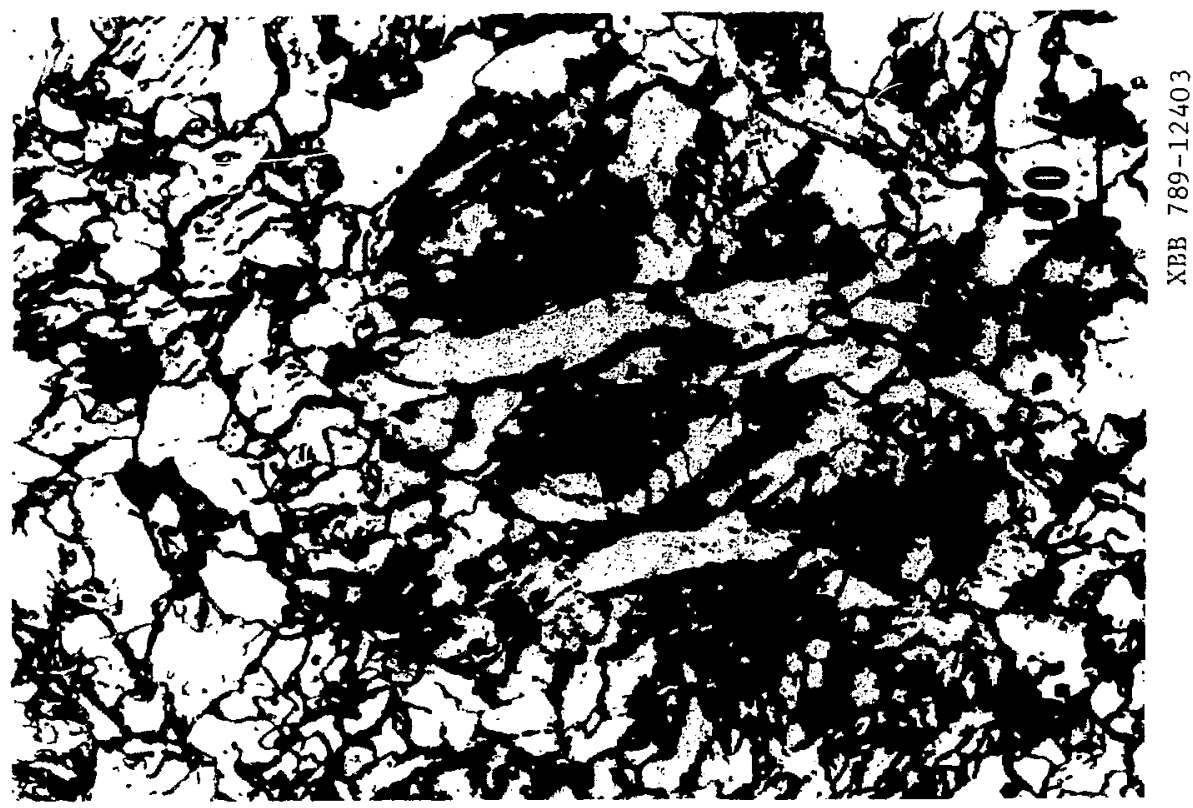

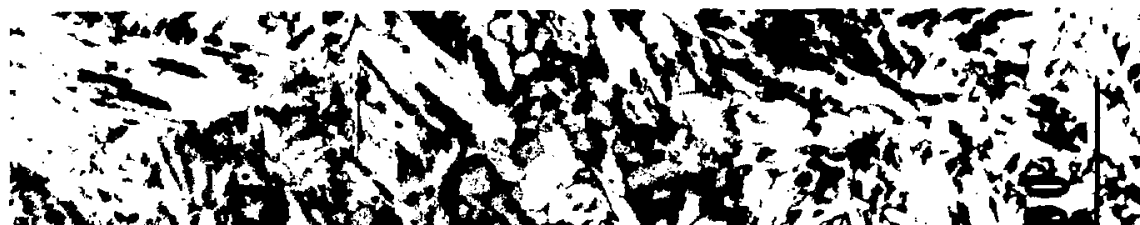

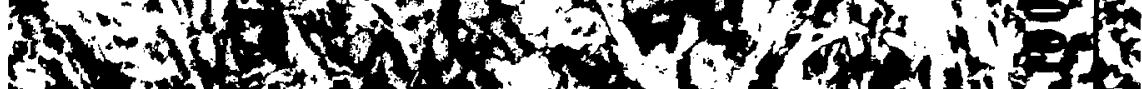

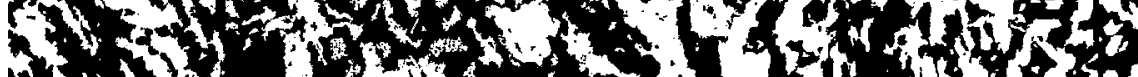
H.

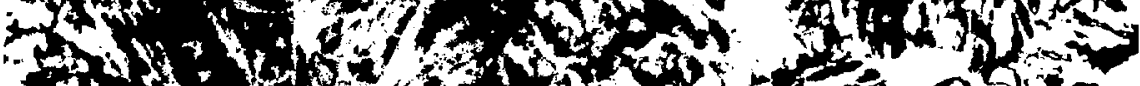

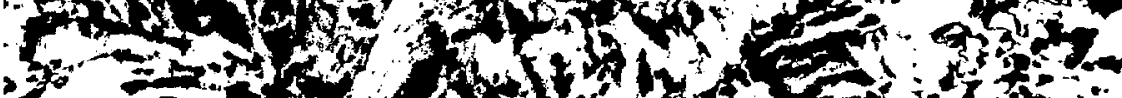

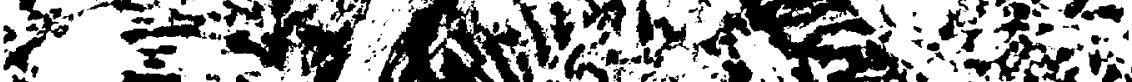

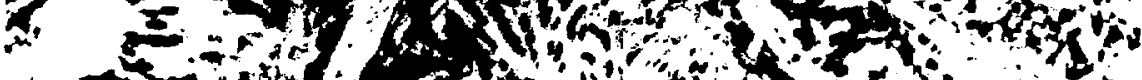
1-men

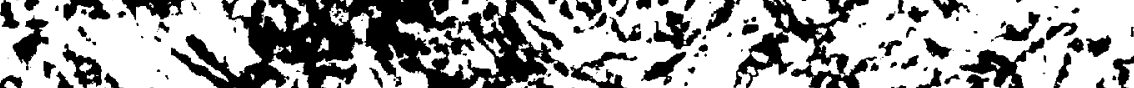
r. $\therefore$ of

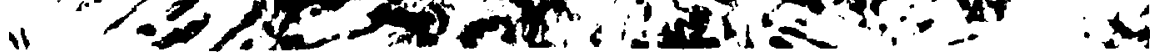




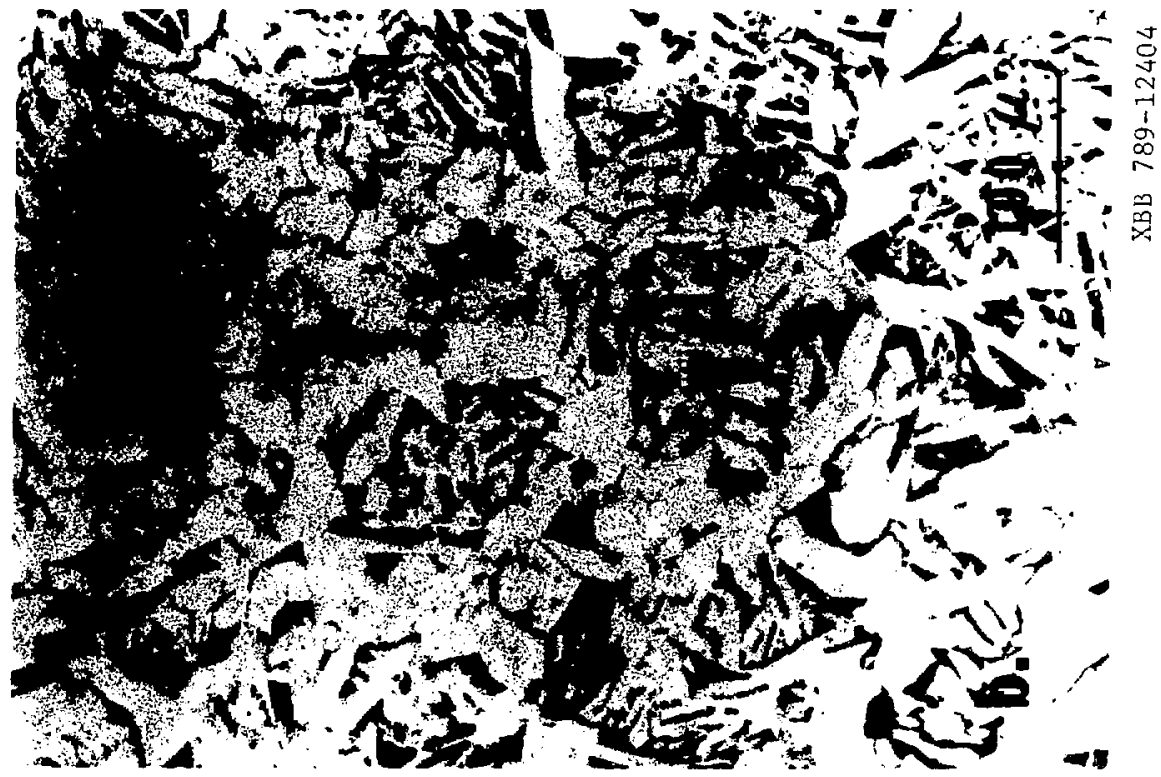

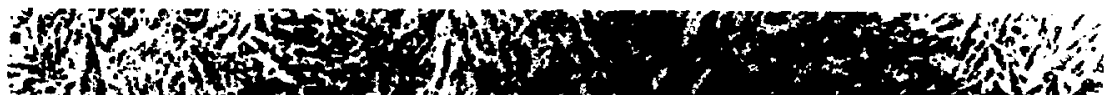

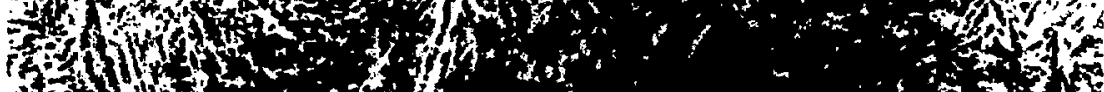

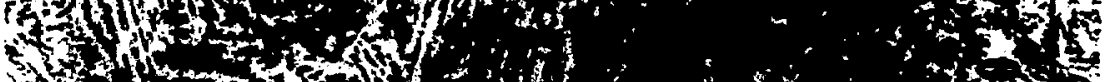

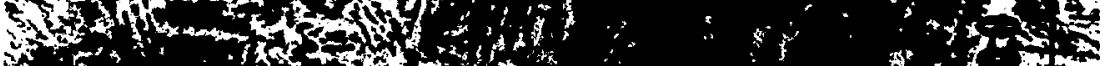

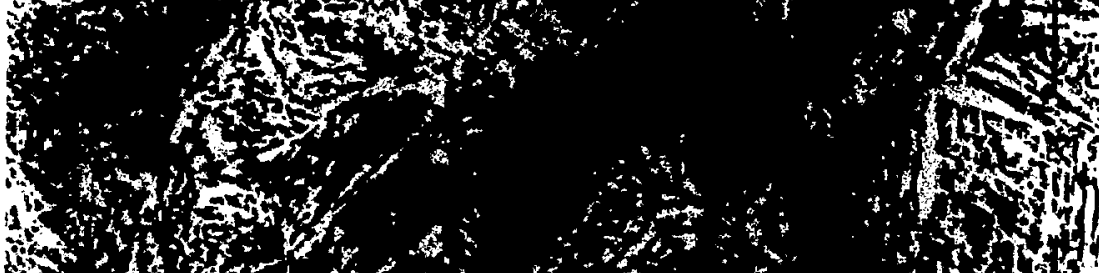

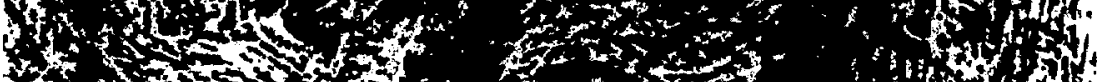

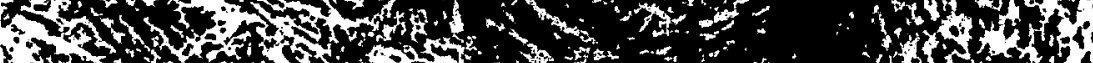

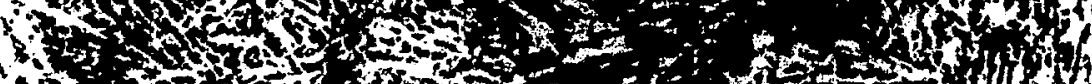

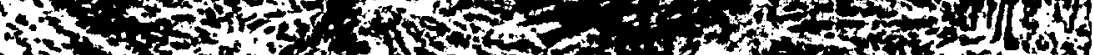
2.

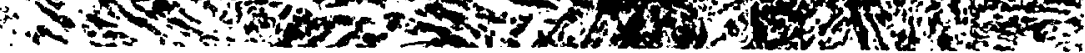




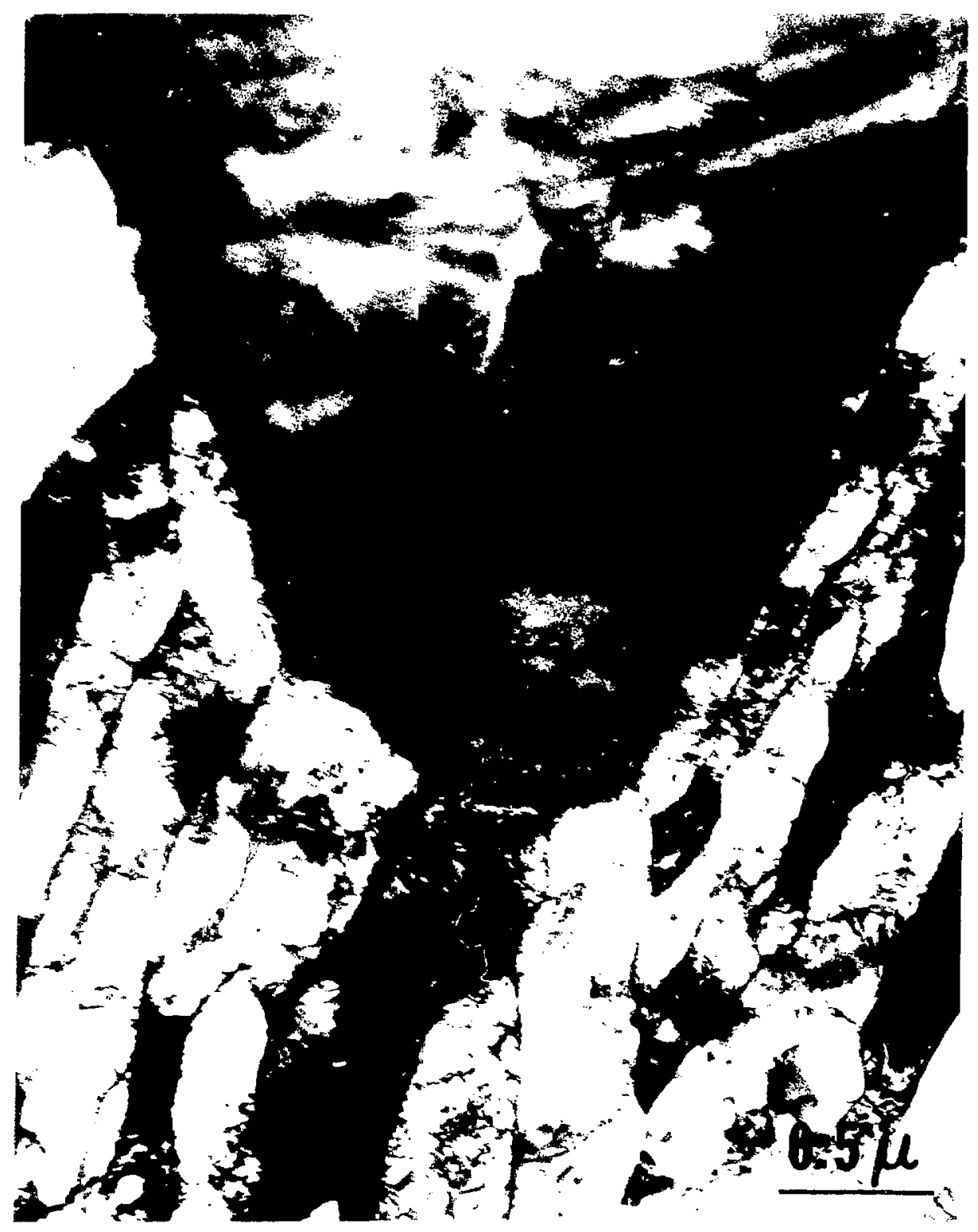

ABB $780-15908$ 


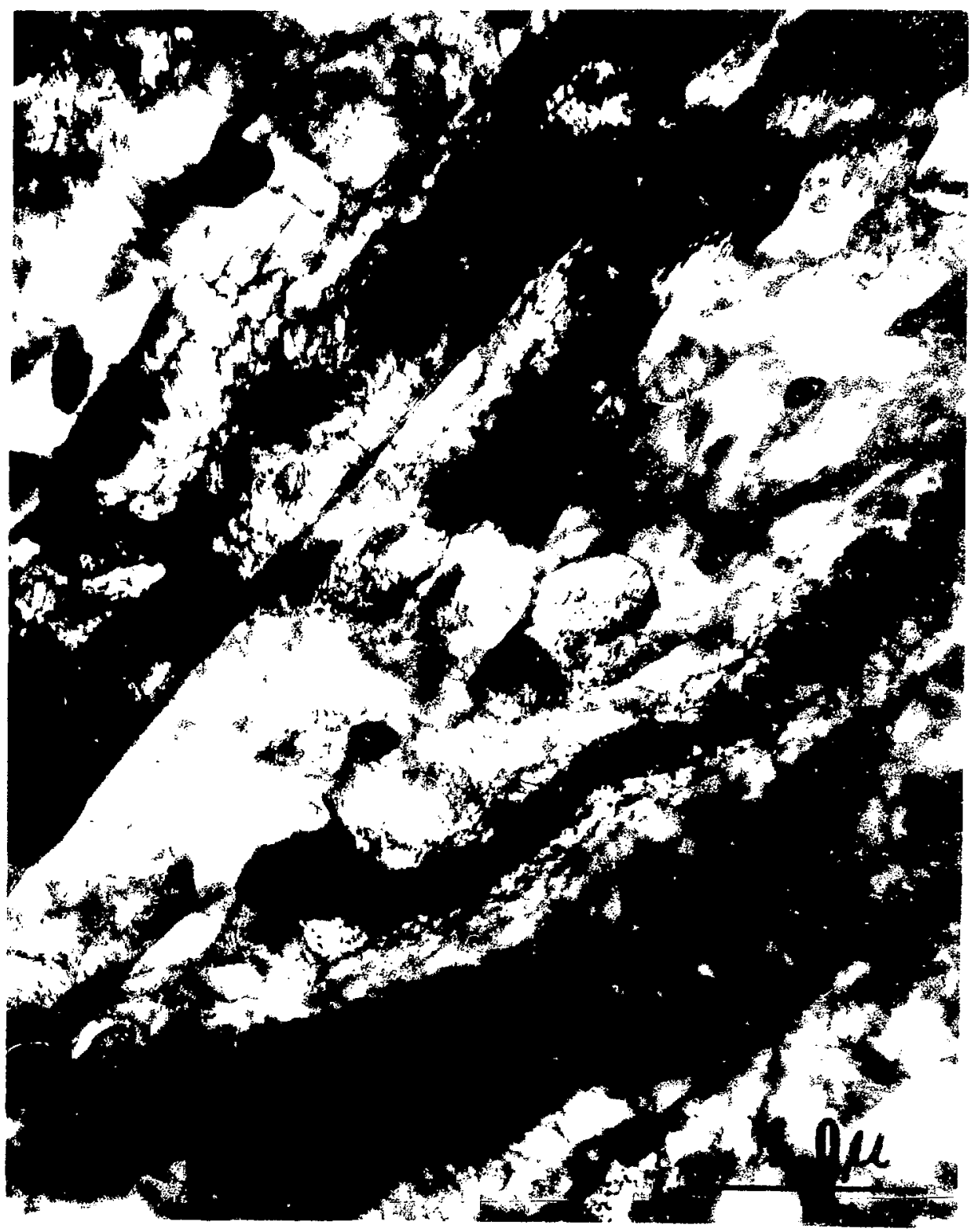

¿lils 780-', 


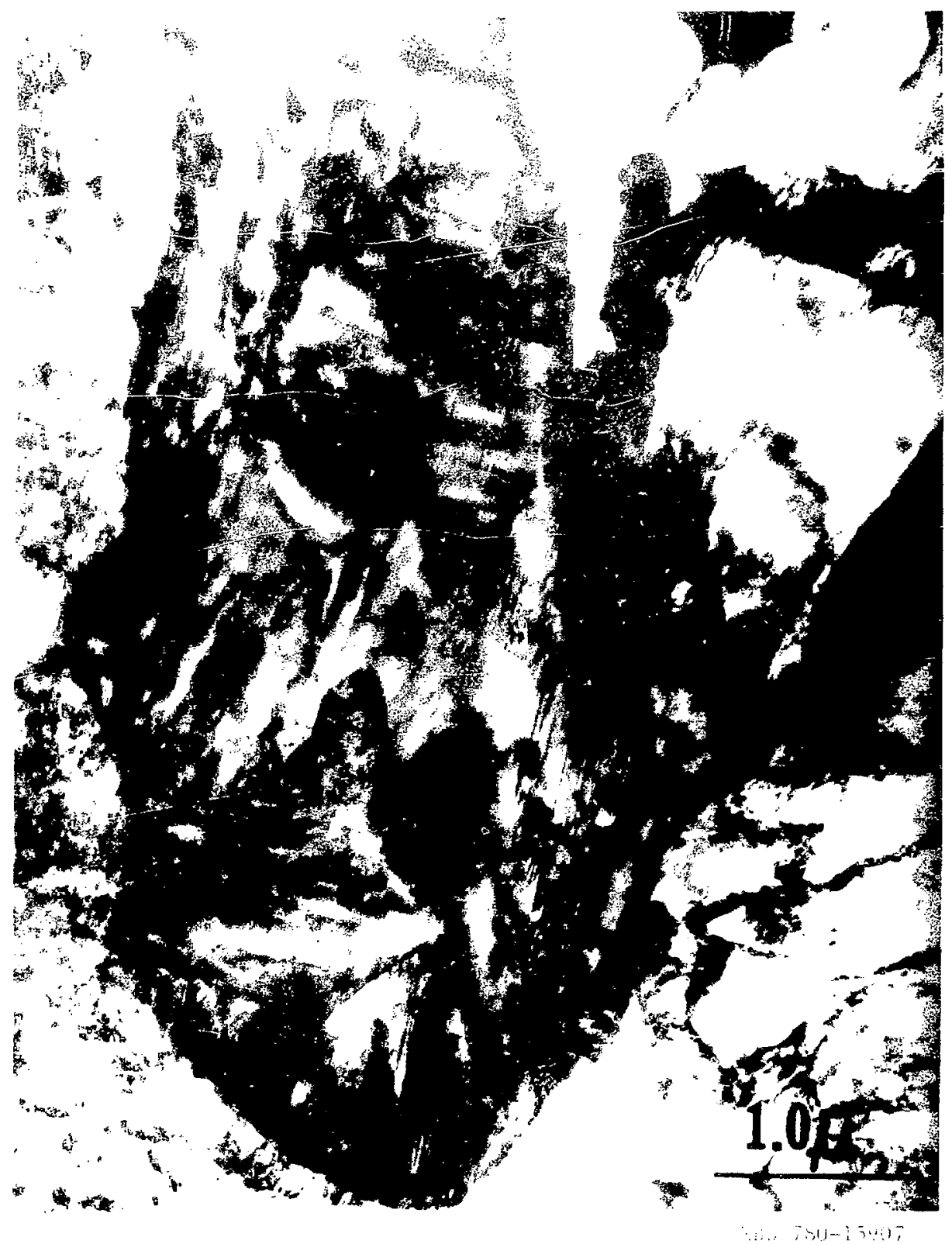




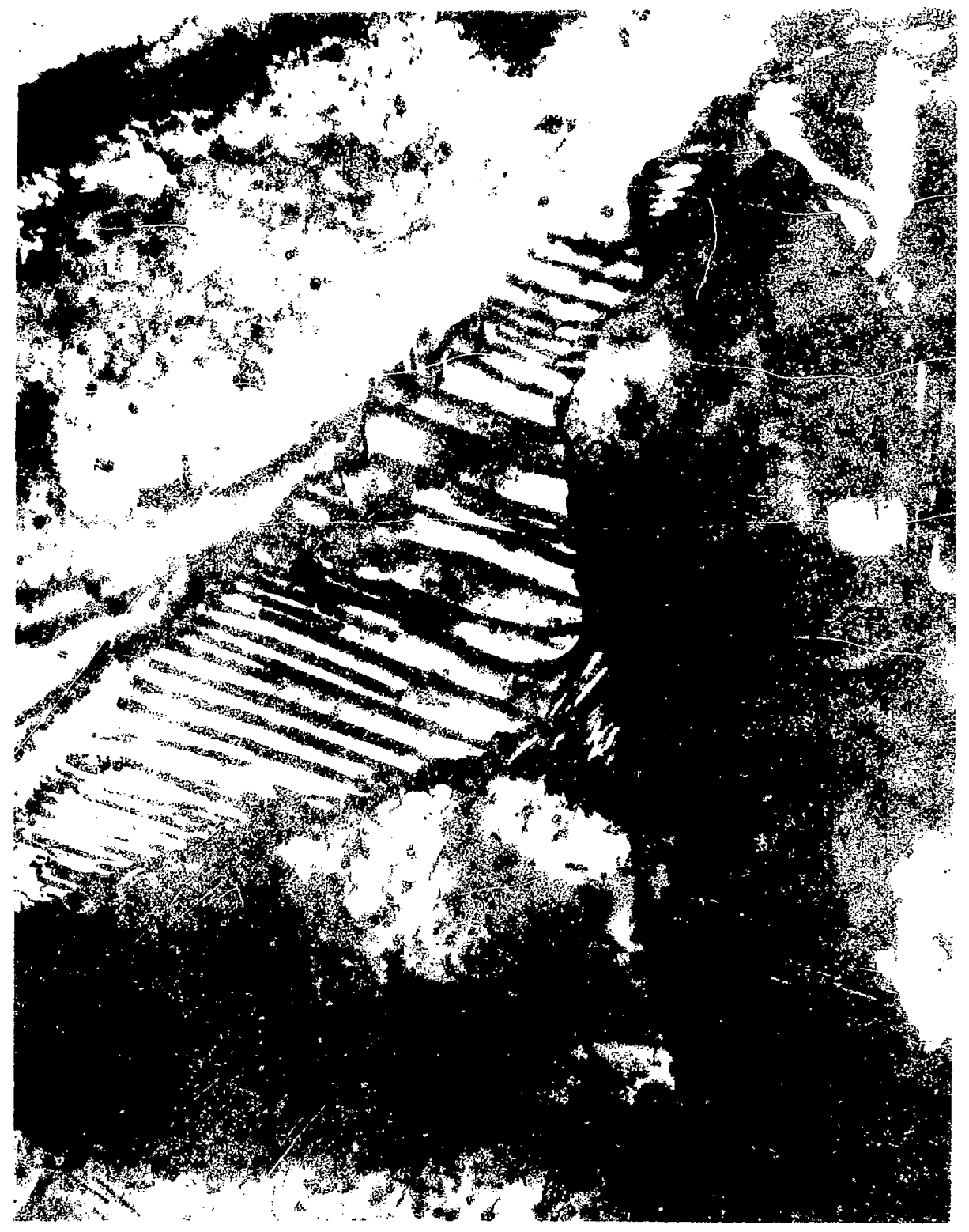



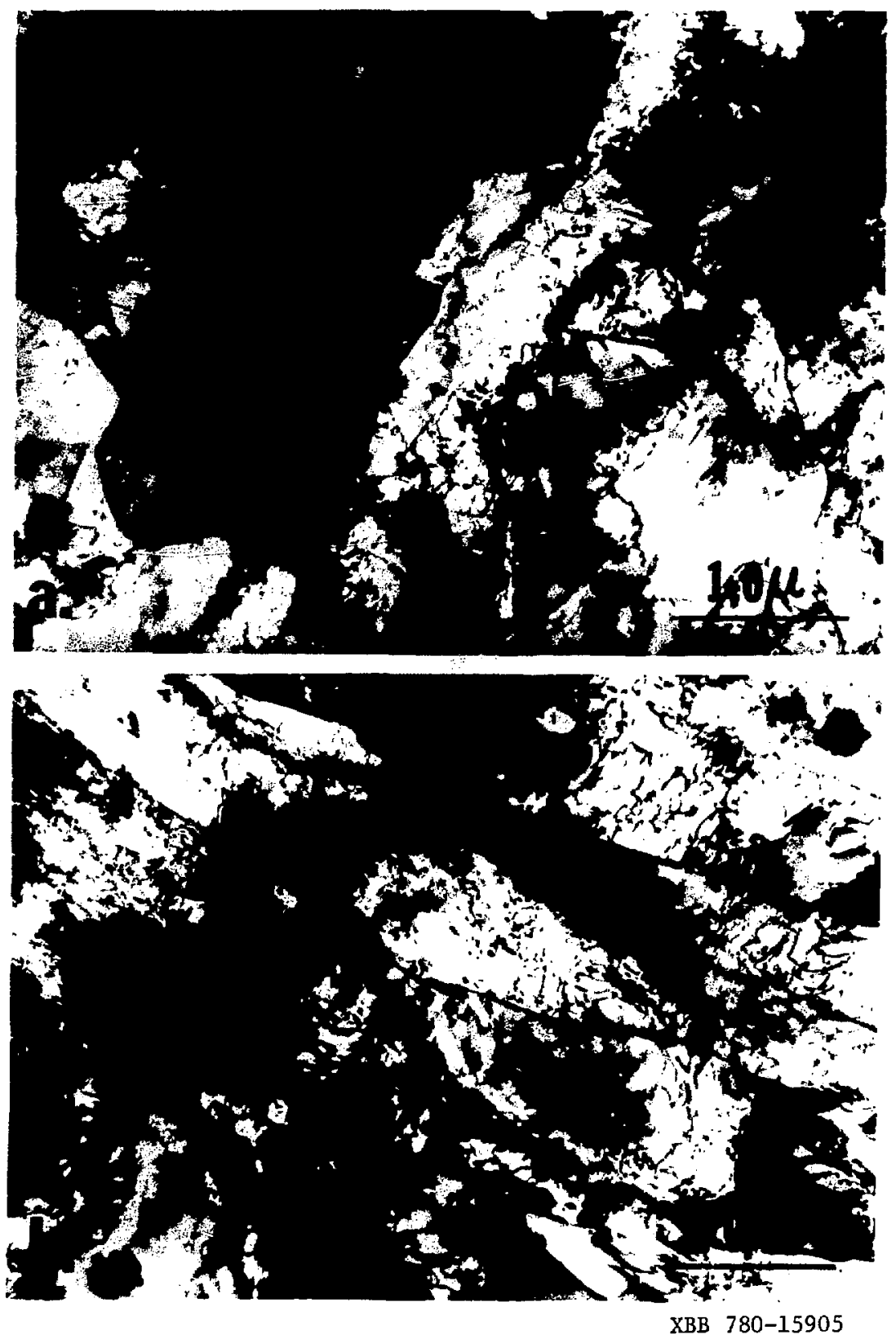

Fig. 13 


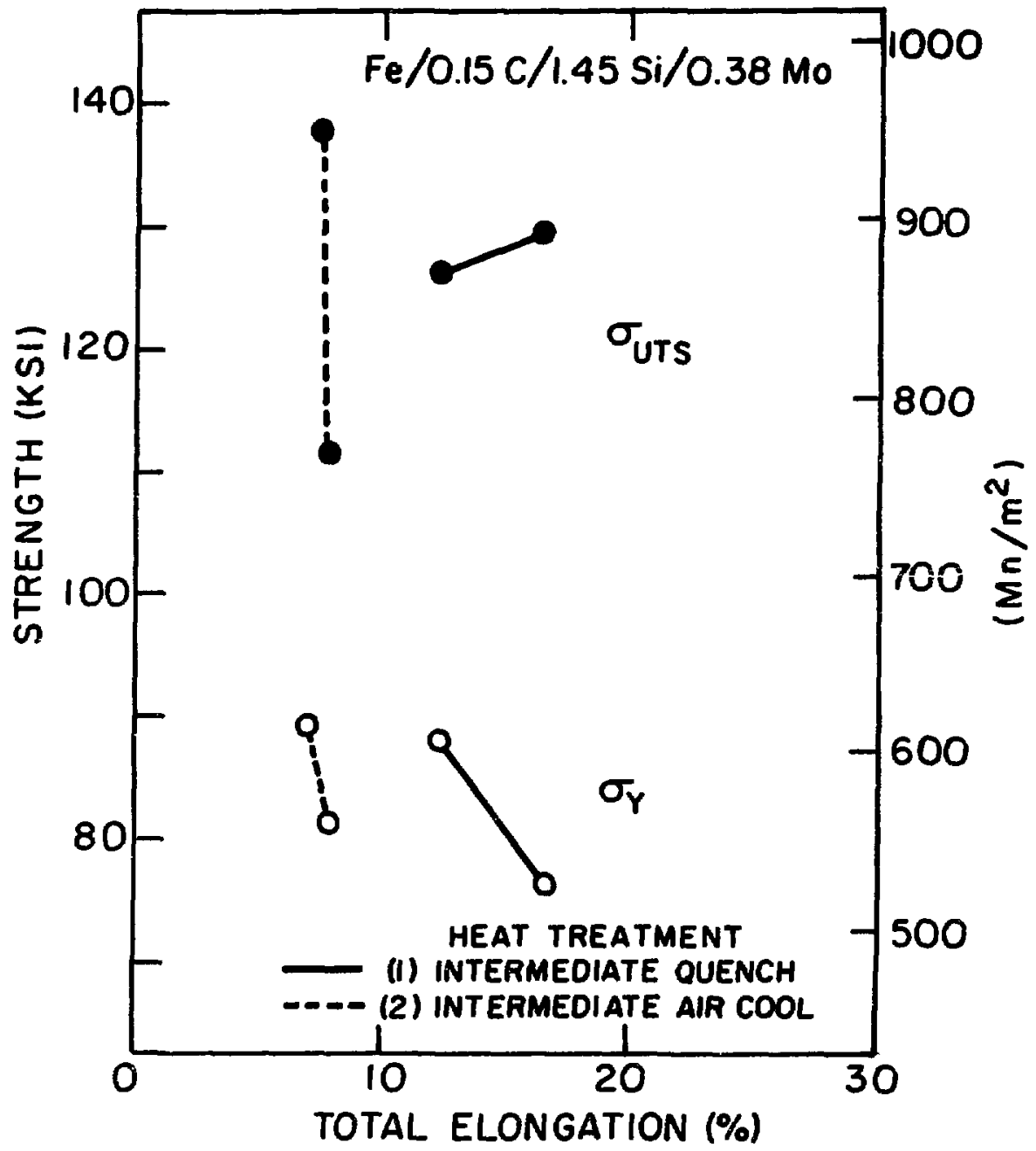

XBL 789.5843

Fig. 14 


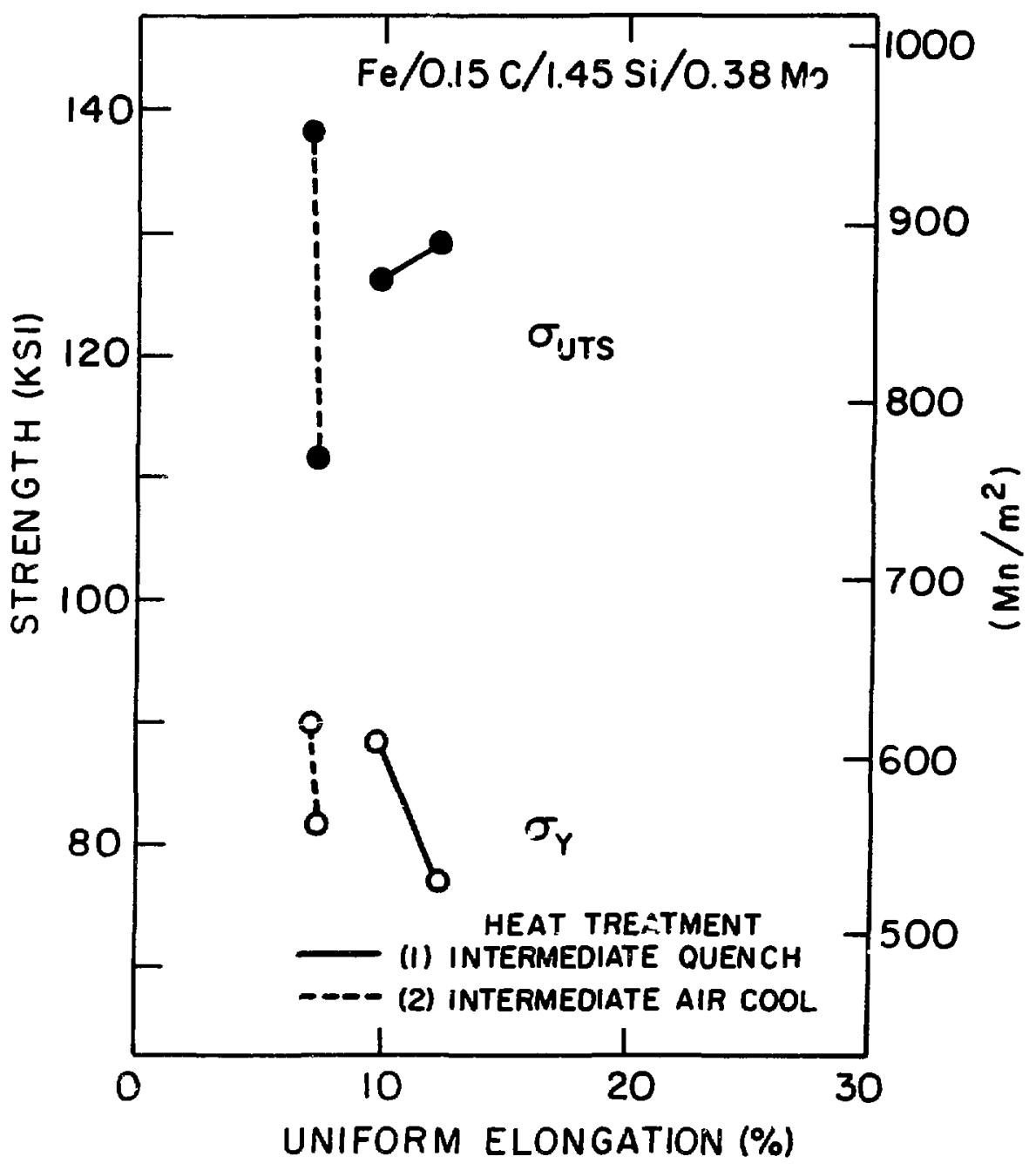

XBL 789-5842

Fig. 15 


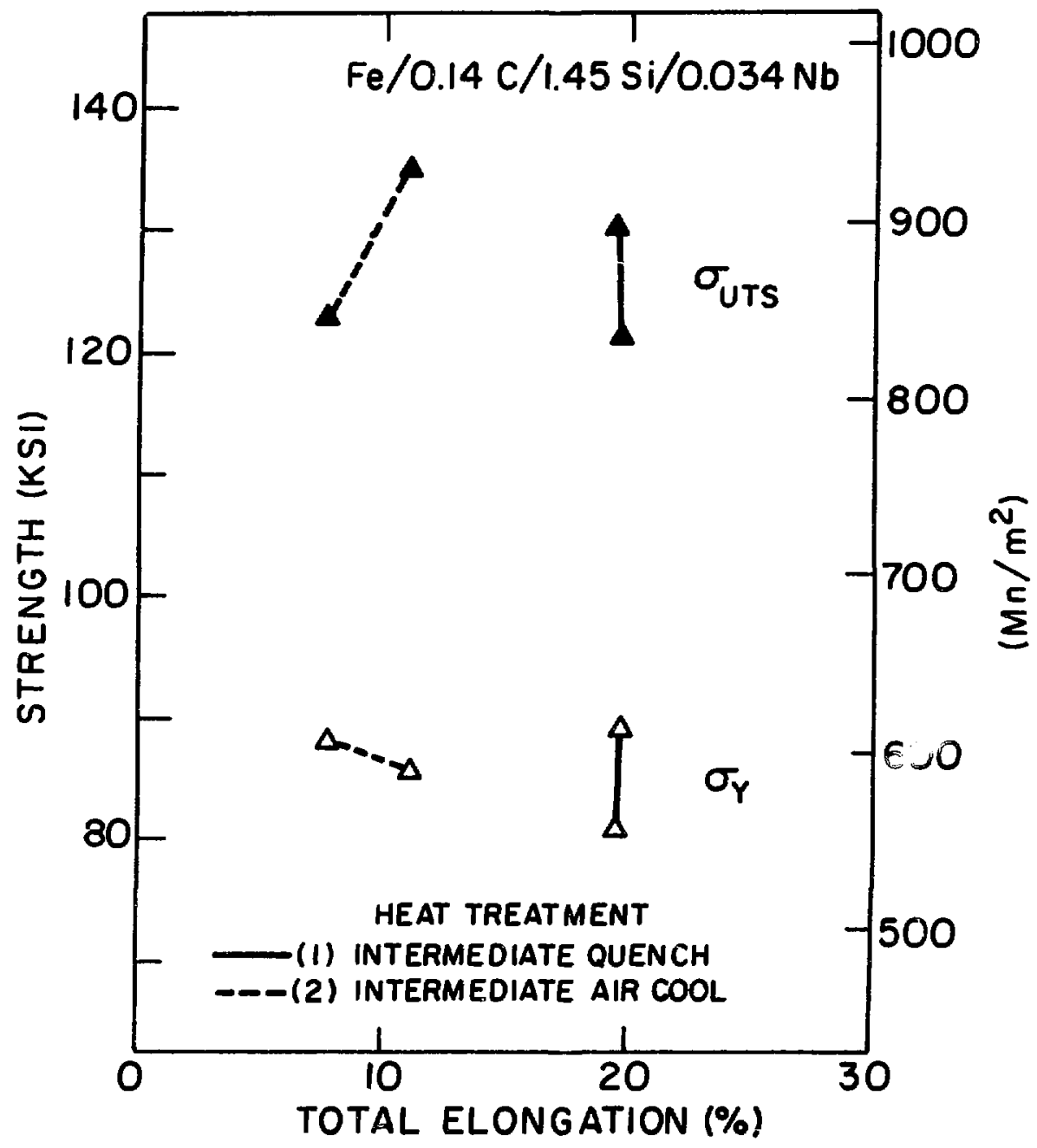

Fig. 16

X 8L 789.5840 


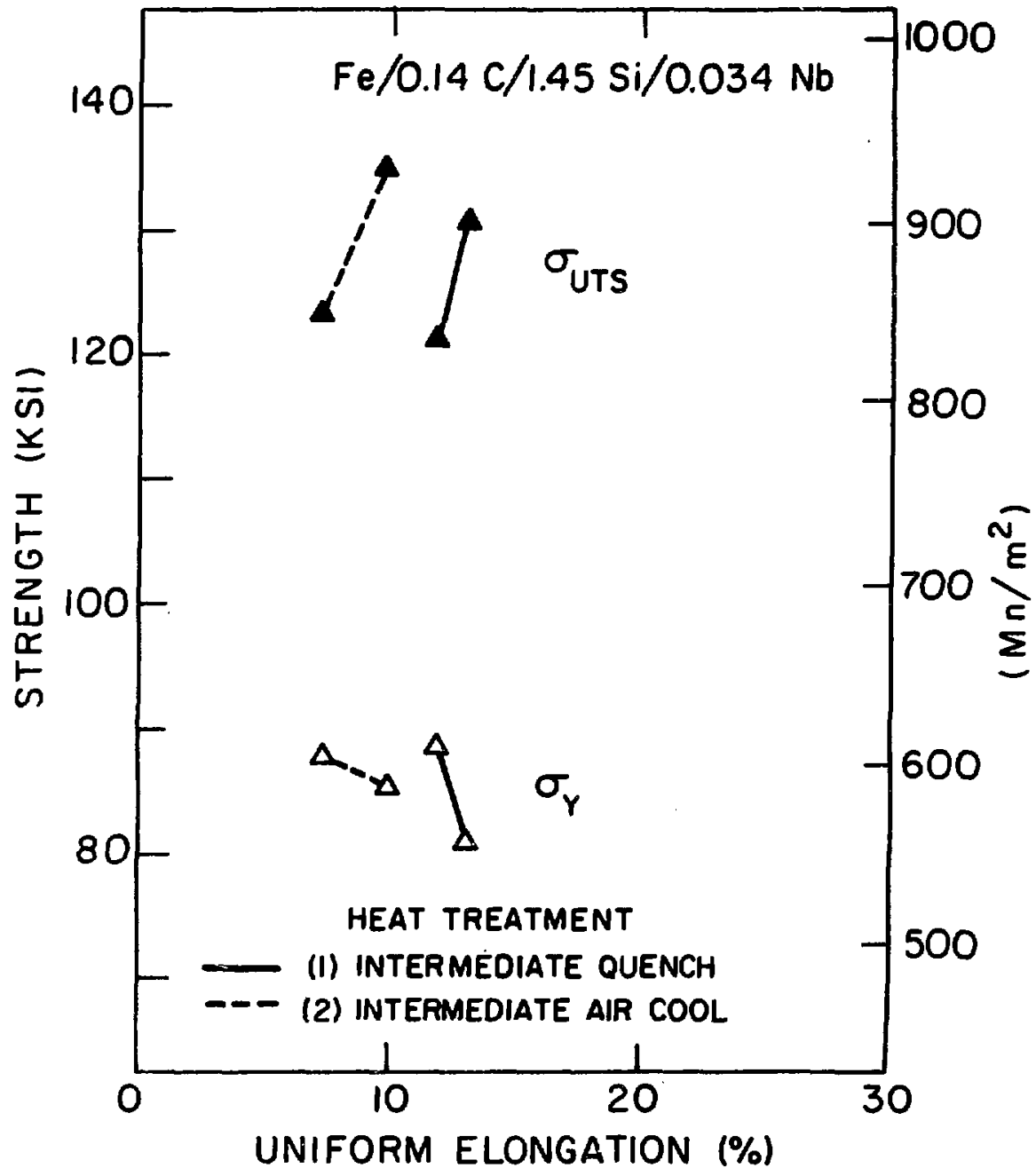

Fig. 17

XBL 789-5838 


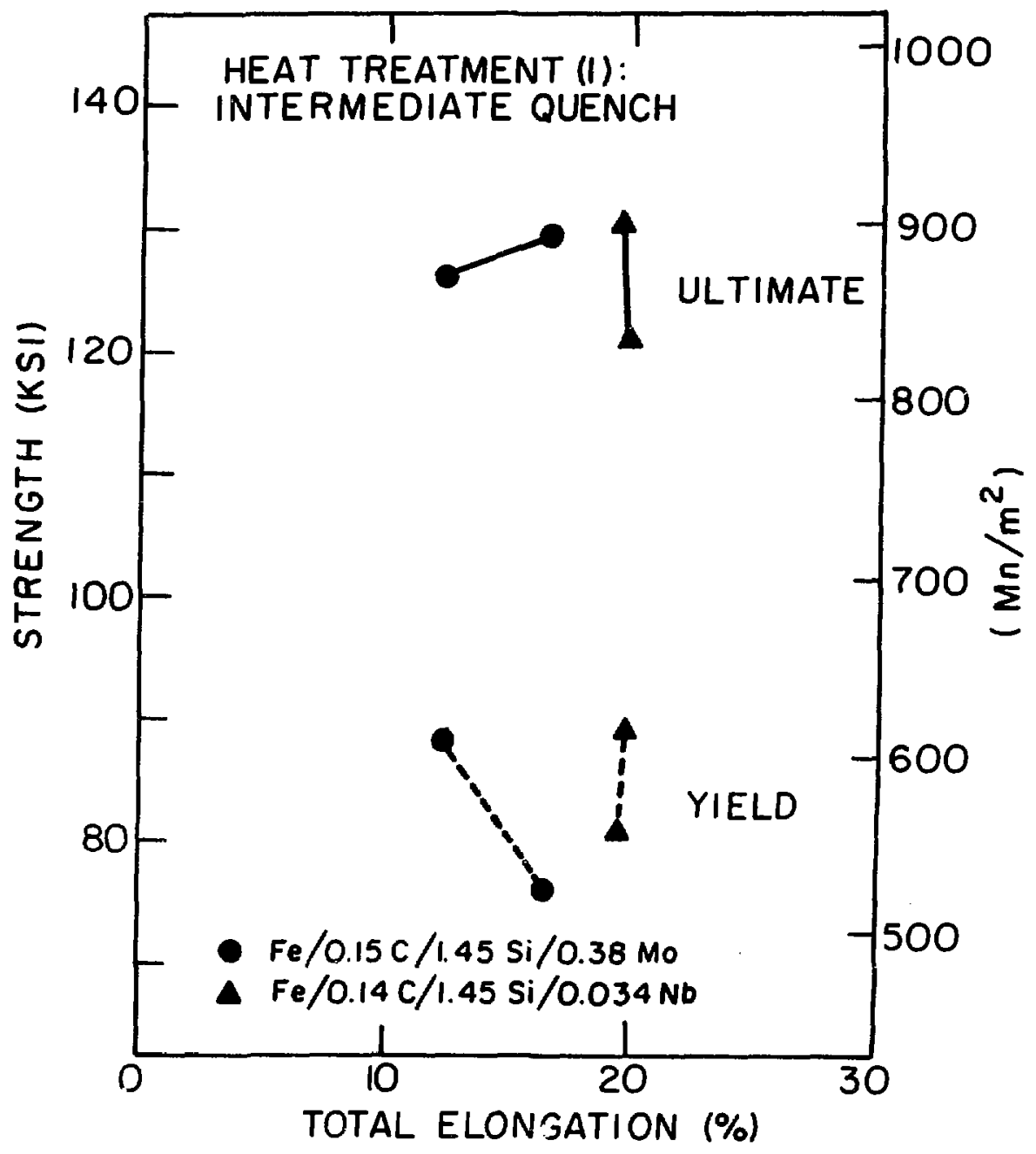

Fig. 18

XBL 789-584। 


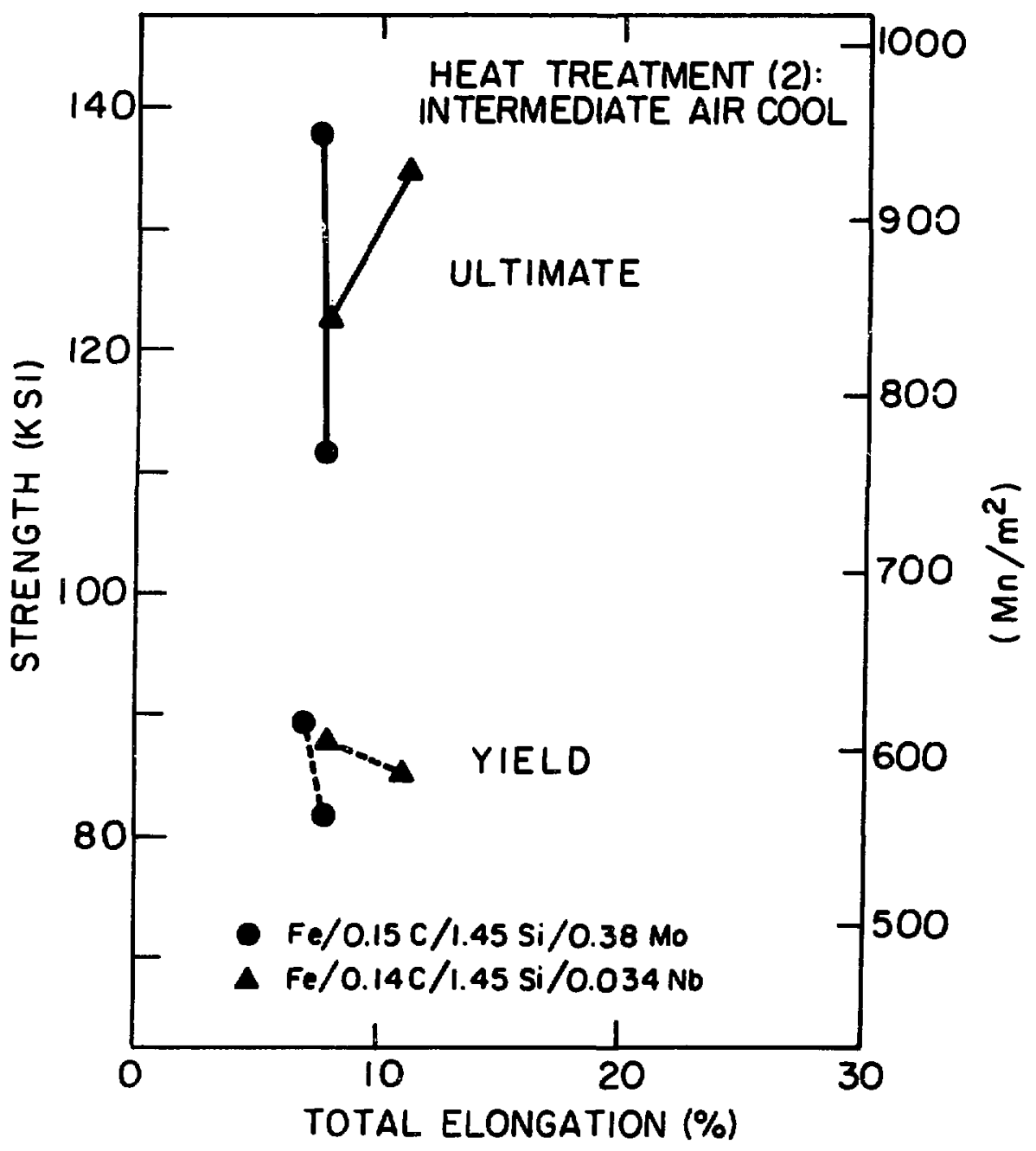

XBL 789-5844

Fig. 19 


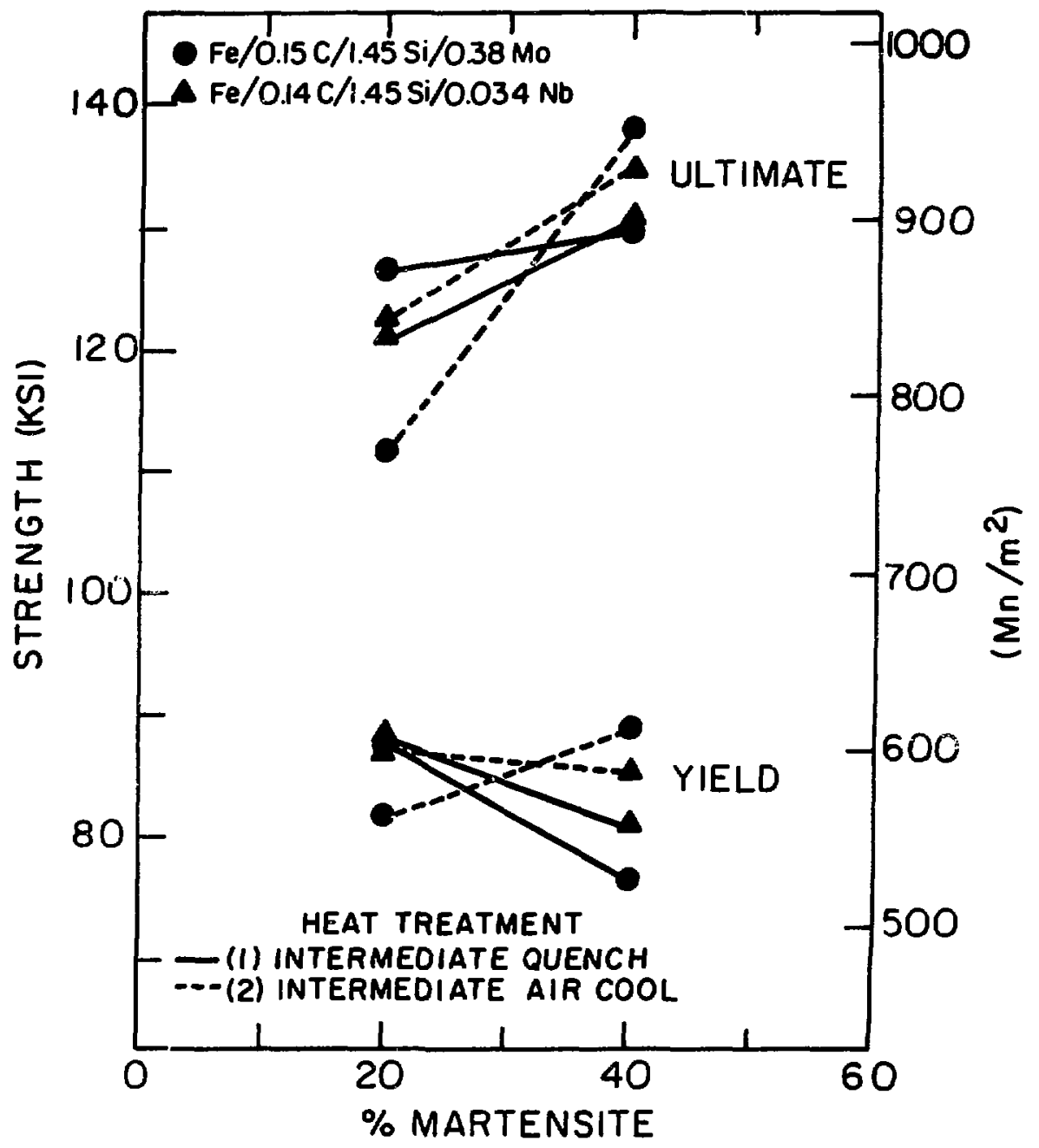

F1g. 20

$X B L 789-5845$ 


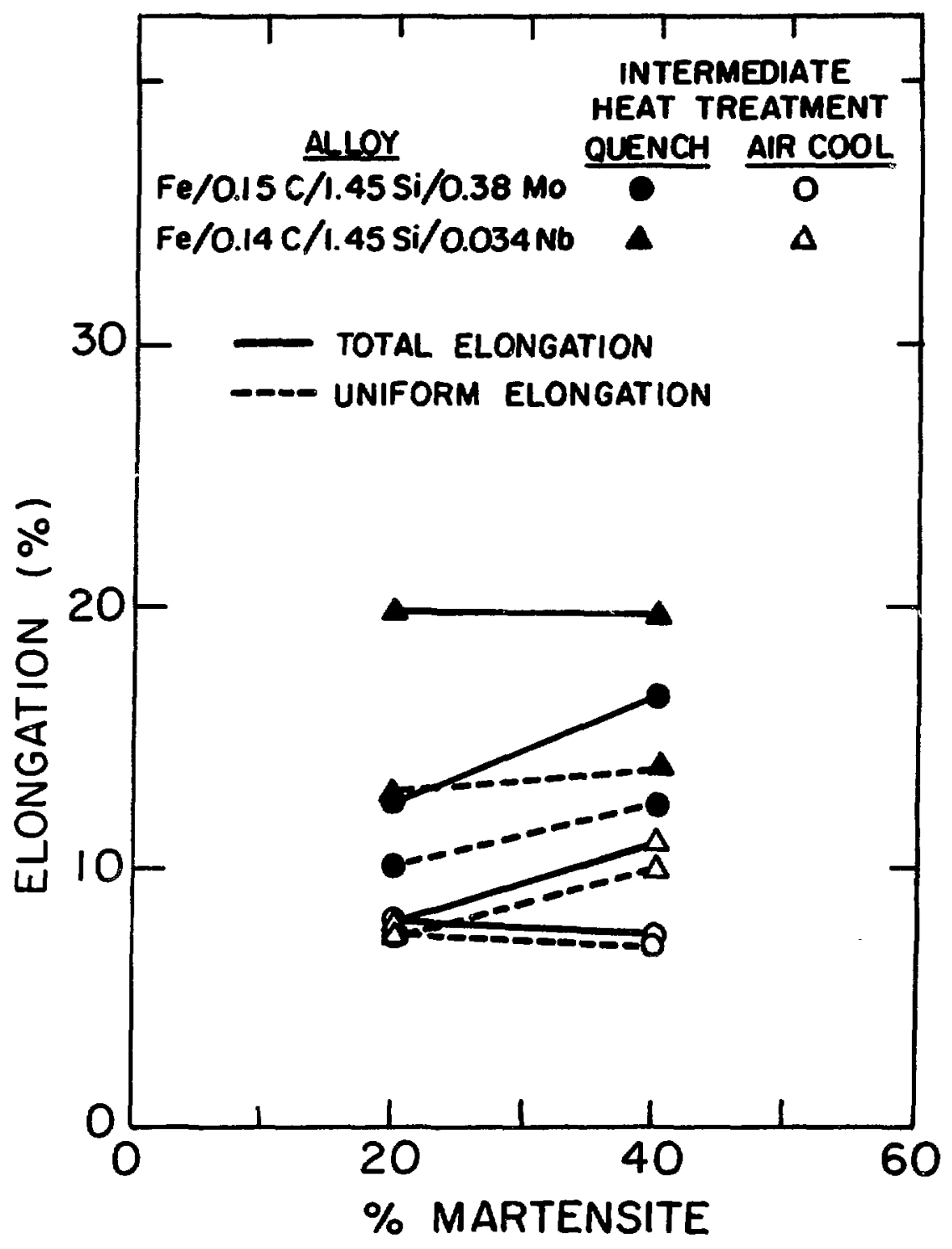

Fig. 21

XBL 789-5839 


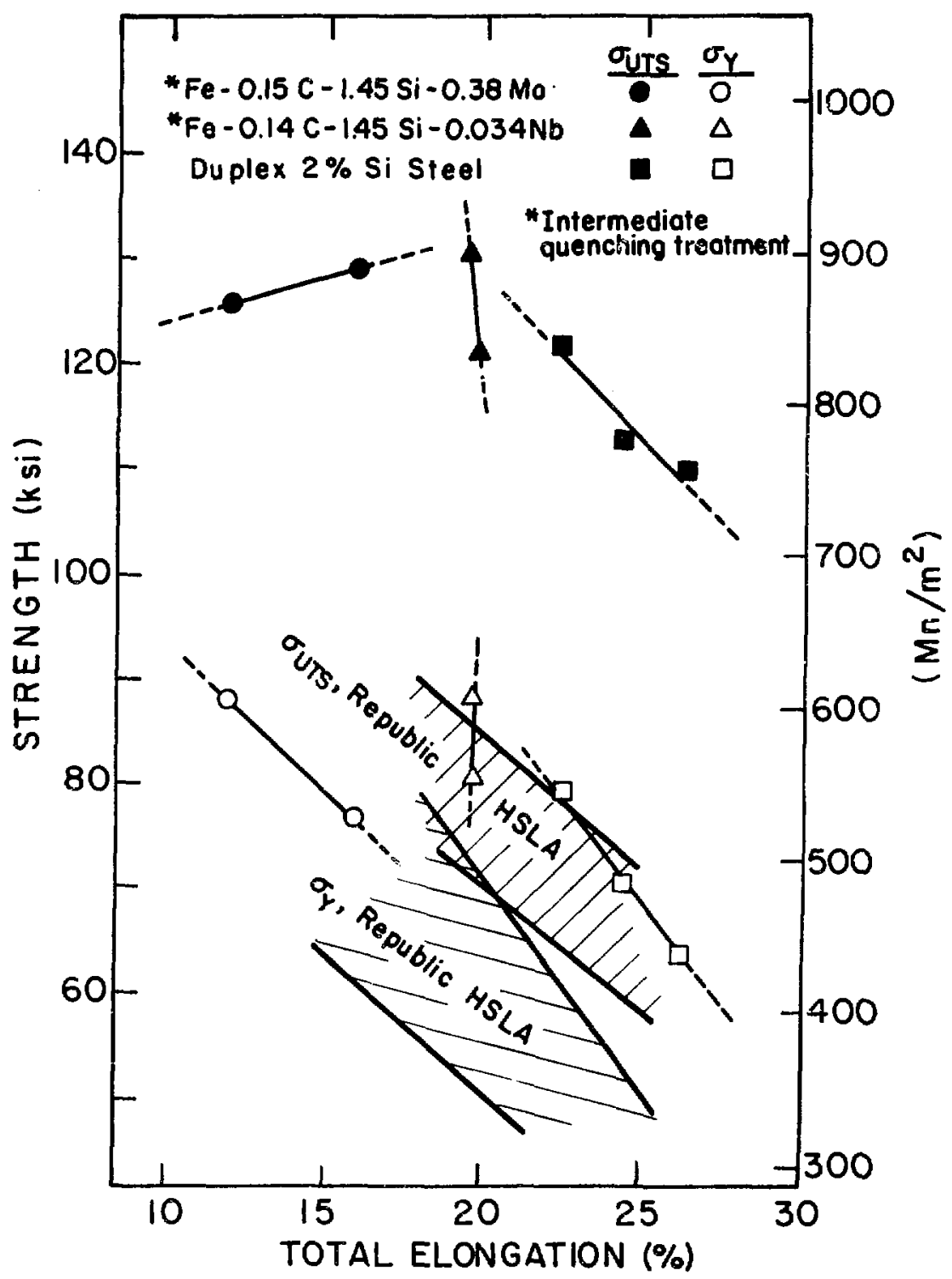

XBL7811-6196

Fig. 22 